\title{
Poder de negociación y brecha salarial de género: caso chileno
}

\author{
Gabriel Cruz \\ Pontificia Universidad Católica de Chile
}

\begin{abstract}
Resumen
A través de la metodología planteada por Card, Cardoso y Kline (2013), que utiliza un modelo de dos efectos fijos de empleado y firma, este artículo estudia el efecto del poder de negociación de hombres y mujeres sobre la brecha salarial de género. Para el cálculo del modelo se utilizó técnicas estadísticas recientemente planteadas por Ouzad (2008) que se basan en Abowd, Creecy, Kramarz (2002). Para esto se usó la base de datos del Seguro de Cesantía chileno, que tiene una rica información conectada de empleado-firma, lo cual permite seguir la movilidad mensualmente de los individuos en distintas firmas entre los años 2002 y 2013. Los resultados encontrados para el caso chileno son que la brecha salarial de género es de $27,4 \%$ y que el poder de negociación explica aproximadamente el $27 \%$ de la brecha salarial, superando el resultado encontrado en Portugal (Card, Cardoso y Kline, 2013). Además, se encuentra que las mujeres aumentan su salario aproximadamente un $15 \%$ menos, en promedio, que los hombres al cambiarse de firma. Todos estos resultados son comparados y discutidos con los encontrados en Portugal en el estudio de Card, Cardoso y Kline (2013).
\end{abstract}

Palabras clave: Brecha salarial de género, poder de negociación, igualdad de género.

\section{Bargaining power and gender pay gap: the Chilean case}

\begin{abstract}
Through the methodology proposed by Carl, Cardoso and Kline (2013), which uses a two fixed effects model employee and firm, this article examines the effect of bargaining power of men and women on the gender pay gap. Model for calculating statistical techniques recently raised by Ouzad (2008) based on Abowd, Creecy, Kramarz (2002) was used. For this database Seguro de Cesantía chileno, which has a wealth of information connected employee-signature was used, which allows to follow the monthly mobility of individuals in various firms between 2002 and 2013. The results for the Chilean case are that the gender pay gap is $27.4 \%$ and the bargaining power accounts for about $27 \%$ of the wage gap, overcoming found in Portugal (Card, Cardoso and Kline, 2013). In addition, it is found that women increase their wages by about $15 \%$ less on average than men to change their signature. All these results are compared and discussed with those found in Portugal in studying Card, Cardoso and Kline (2013).
\end{abstract}

Keywords: Gender wage gap, bargaining power, gender equality.

\section{Poder de negociación y brecha salarial de género ${ }^{1}$}

Desde los inicios del siglo pasado ha existido un interés por hacer a la mujer partícipe de los procesos sociales, económicos y políticos. Por ejemplo,

\footnotetext{
${ }^{1}$ Esta investigación utilizó información de la Muestra Representativa de la Base de Datos de los Afiliados al Seguro de Cesantía, de la Superintendencia de Pensiones. Todos los resultados del estudio son de responsabilidad del autor y en nada comprometen a esa Superintendencia

*Dirección de correspondencia [Correspondence address]:

Gabriel Cruz, Pontificia Universidad Católica de Chile E-mail: gjcruz@uc.cl
}

para organizaciones internacionales como las $\mathrm{Na}-$ ciones Unidas, la igualdad de género en el trabajo ha sido una lucha constante, partiendo por el Tratado de Paz de Versalles de 1919, donde se indica que las mujeres deben recibir igual remuneración para trabajos de igual valor que los hombres². En 1951, la Organización Internacional del Trabajo (OIT) declara la igualdad de remuneraciones entre la mano de obra masculina y femenina por un trabajo de igual valor, declaración que Chile ratificó veinte años después. Dos décadas más tarde, la Convención sobre la eliminación de todas las formas de discriminación contra la mujer (CEDAW $)^{3}$ anuncia que los estados deben adoptar todas las

\footnotetext{
2 "Treaty of Peace between the Allied and Associated Powers and Germany", firmado el 28 de Junio de 1919 en París.

${ }^{3}$ The Convention on the Elimination of all Forms of Discrimination against Women (1979).
} 
medidas apropiadas para eliminar la discriminación contra la mujer en el mercado laboral ${ }^{4}$.

En Chile, en el año 2009 se promulgó la Ley 20.348 que establece la igualdad de remuneraciones, permitiendo que la mujer pueda presentar un reclamo si es dis-criminada salarialmente. Sin embargo, aún queda mucho que aportar e investigar sobre las causas de la brecha salarial de género para que en un futuro se pueda llegar a una verdadera igualdad laboral.

La literatura económica tradicionalmente ha asociado la brecha salarial con distintas teorías, como la discriminación laboral que sufren las mujeres, la diferencia de acumulación de capital humano por género (Altonji y Blank, 1999), el sector económico en el que se emplean (Jarrell y Stanley, 2004), los costos laborales asociados a la contratación femenina (Abramo y Todaro, 2002), entre otras hipótesis. No obstante, ha habido un crecimiento en los últimos diez años de nuevas teorías que buscan otras explicaciones sobre las causas de la diferencia salarial.

Por el lado empírico, la literatura económica ha utilizado una gran variedad de datos para estudiar la desigualdad salarial. Diversos estudios han concluido que la oferta, la demanda y las instituciones contribuyen a la brecha salarial, aunque en diferentes rangos en cada país y períodos del tiempo (Katz, 1999). Sin embargo, la mayoría de los estudios se han enfocado en los empleados y sus habilidades observables, dejando de lado las características del empleador, dado el difícil acceso a estos datos. Esto constituye un problema, ya que economistas teóricos han destacado que la heterogeneidad de firmas genera diferencias salariales entre trabajadores con idénticas habilidades dentro de un mismo sector económico (Lentz y Mortensen, 2010; Burdett y Mortensen, 1998).

Por ejemplo, Gruetter y Lalive (Gruetter y Lalive, 2009) investigan la importancia de la firma en la diferencia salarial entre individuos e industria. Además, estudian la movilidad de trabajadores que se trasladan de un trabajo directamente a otro y de trabajadores que se mueven de trabajo pero pasando por un período de desempleo. Los autores llegan a la conclusión de que la firma explica mucho más la varianza de salario entre industrias que entre individuos y al analizar empleados que se trasladan de trabajo directamente, reducen la importancia del efecto firma en la explicación de la diferencia salarial. En el mismo sentido, Card, Heining y Kline

\footnotetext{
${ }^{4}$ Algunos de los derechos pleanteados por el artículo 11 son: a igual remuneración, a elegir libremente profesión y empleo, a las mismas oportunidades de empleo, a implantar licencia de maternidad con sueldo pagado y a la protección especial durante el embarazo
}

(2013b) encuentran que los cambios en los salarios se ven afectados por características individuales de los empleados y también por un componente del trabajador que está trabajando en una empresa específica.

Gracias a los avances experimentales en psicología y su creciente influencia en la literatura económica, existe una idea de factores psicológicos que parecen diferir sistemáticamente entre hombres y mujeres y que pueden afectar la brecha salarial de género (Marianne, 2011), tales como las preferencias de riesgos, las actitudes hacia la competencia y el poder de negociación (Rudman y Glick, 1999; Rigdon, 2012; Bowles et al., 2005; Card et al., 2013a)

Específicamente, este trabajo busca aportar a la nueva literatura de la brecha salarial de género a través de la teoría de poder de negociación. Esta nueva hipótesis señala que las mujeres obtienen una parte más pequeña de las ganancias de las empresas que los hombres, dado el menor poder de negociación que tienen.

La literatura ha utilizado bases de datos extensas con información del individuo contratado y del empleador, que permite identificar separadamente el efecto empleado y el efecto empresa. Estas bases de datos panel están disponibles en diferentes países como en Francia, Dinamarca, Noruega, Italia, Chile y Brasil gracias a programas como el Seguro de Cesantía. En Chile, esta política - por la cual todos los trabajadores con contratos se afilian automáticamente al programa de Seguro de Cesantía - fue implementada en octubre de 2002.

Para aportar a esta nueva teoría se implementará el modelo planteado por Card, Cardoso y Kline (2013a), que utilizan un modelo de dos efectos fijos de empleado y firma. Para el cálculo de estos efectos se utilizará la metodología estadística planteada por Ouzad (2008), que se basa en Abowd, Creecy, Kramarz (2002).

Este es el segundo trabajo que utiliza esta nueva metodología para estudiar la teoría del poder negociación sobre la brecha salarial de género, después de su aplicación en Portugal. Los resultados encontrados para el caso chileno son que la brecha salarial de género es de $27,4 \%$ y que el poder de negociación explica aproximadamente el $27 \%$ de la brecha salarial superando el resultado encontrado en Portugal (Card et al., 2013a). Además, se encuentra que las mujeres aumentan su salario aproximadamente un $15 \%$ menos, en promedio, que los hombres al cambiarse de firma. 


\section{Brecha salarial, contexto chileno y re- gulación}

En las últimas décadas la mujer ha tenido una alta incorporación al mercado laboral chileno. Henríquez y Riquelme (2011) indican que la participación laboral femenina pasó del 30,9\% en los años 90, a 41,3\% en el año 2009; y el porcentaje que las mujeres aportan al ingreso del hogar pasó del $28,7 \%$ al 38,6\%. Además, un tercio de los hogares chilenos tienen como jefa a una mujer y esta proporción crece al 43,2\% en los hogares pobres y a un $47,9 \%$ en los indigentes, donde muchas veces este es el único ingreso del hogar. También señalan que en los hogares con menores ingresos la mujer aporta un porcentaje aún mayor al ingreso familiar y que en la población más rica el $25 \%$ es aportado por las mujeres, mientras que, en los más pobres, su aporte sube casi al doble, al 45,2\%.

A pesar de que durante los últimos veinte años las políticas públicas sobre la incorporación de la mujer a la fuerza de trabajo han tenido resultados positivos, existen consideraciones que hay que tener en cuenta. Por ejemplo, la incorporación no ha sido homogénea; existiendo segregación de género en las industrias (Henriquez y Riquelme, 2011). Muchas veces esto ha hecho que las mujeres estén en trabajos de menor calidad que los hombres. La Encuesta Suplementaria de Ingresos del año 2011 indica que, en los sectores con alta concentración femenina, es amplia la franja de trabajo precario e informal, con baja productividad y mal pagado.

Con respecto a la brecha salarial, según el informe entregado el 2010 por el Programa de Naciones Unidas por el Desarrollo (PNUD), el salario promedio en Chile de las mujeres es entre $20 \%$ a $30 \%$ menor al promedio del de los hombres. Esta diferencia aumenta en trabajadores con educación superior. Sin embargo, este porcentaje es bastante inferior al de los años sesenta, cuando las mujeres obtenían la mitad del salario promedio que ganaban los hombres.

En el cuadro 1 se observa que la brecha salarial de género promedio por hora aumenta en la medida en que lo hace el nivel educacional. La brecha supera el $35 \%$ en trabajadores con educación universitaria sin y con postgrado, mientras que en el segmento con educación básica es de 13,9\%. Esto indica que posiblemente en los cargos más altos existe una diferencia mayor en el poder de negociación que tienen los hombres y las mujeres en comparación a cargos menos calificados. Esto se puede deber al hecho de que las mujeres que se encuentran en altos cargos tienen mucho más que perder al momento de negociar en comparación con las mujeres que se encuentren en puestos de menores salarios, lo que se traduce en un menor poder de negociación en trabajos de alta calificación.

\section{Metodología}

\section{Modelo general}

Desarrollado por Card, Cardoso y Kline (2013a), este modelo permite evaluar el efecto del poder de negociación sobre el salario según el género del trabajador. De esta manera, este trabajo aportará a la nueva literatura de la brecha salarial utilizando datos de Chile.

En el modelo, el trabajador $i$ es observado en múltiples períodos $t$. En el período $t$ el individuo $i$ trabaja en la firma $j=j(i, t)$. Además, se denota el género del trabajador $i$ por $g \in\{F, M\}$.

Siguiendo un modelo salarial, el trabajador gana un salario $w_{i j t}$ en cada período, que es igual a su sueldo alternativo de mercado $\left(a_{i t}\right)$ más una extracción de la ganancia $\left(S_{i j t}\right)$ de la firma $j$ en el período $t$, que varía según el sexo del trabajador $\left(\gamma^{g} \in[0,1]\right)$.

$$
w_{i j t}=a_{i t}+\gamma^{g} S_{i j t}
$$

La literatura más reciente argumenta que $\gamma^{F}<$ $\gamma^{M}$, lo que significa que las mujeres obtienen una menor proporción de la renta de la empresa que los hombres, lo cual se traduce en un menor salario.

La ganancia de la firma, $S_{i j t}$, se descompone en tres elementos:

$$
S_{i j t}=\bar{S}_{j}+v_{j t}+m_{i j}
$$

El primer componente, $\bar{S}_{j}$, es el promedio de las ganancias de todos los trabajadores en todos los períodos en la empresa $j$. El segundo componente, $v_{j t}$, es un componente de la empresa variable en el tiempo atribuible a factores como los cambios de producción o los precios de los insumos. El tercer componente, $m_{i j}$, invariante en el tiempo, es atribuible a características del trabajador y de la empresa.

El salario alternativo $\left(a_{i t}\right)$ se descompone, a su vez, en $\alpha_{i}$ que es invariante en $t$, un componente que es una combinación lineal de variables en el tiempo $X_{i t}$ como educación, experiencia, entre otros, y $\varepsilon_{i t}$, que representa habilidades no observables o shocks que varían en el tiempo: 
Cuadro 1: Brecha salarial por nivel educativo

\begin{tabular}{ll}
\hline Nivel educativo & Brecha \\
\hline \hline Educación Básica o Primaria & $13,9 \%$ \\
Humanidades o Educación Media Científico-Humanista & $20,5 \%$ \\
Educación Media Técnica Profesional & $16,5 \%$ \\
Centro de Formación Técnica incompleta & $32,7 \%$ \\
Centro de Formación Técnica completa & $25,8 \%$ \\
Instituto Profesional incompleto & $27,4 \%$ \\
Instituto Profesional completo & $28,7 \%$ \\
Educación Universitaria incompleta & $22,5 \%$ \\
Educación Universitaria completa & $35,4 \%$ \\
Universitaria Postgrado & $37,4 \%$ \\
Total & $15,8 \%$ \\
\hline \hline Nota: Proporción relativa del ingreso y brecha salarial por hora promedio de la ocupación principal de las \\
mujeres asalariadas respecto de los hombres asalariados, según nivel educacional. Fuente: Henríquez y Riquelme
\end{tabular}

eres asalariadas respecto de los hombres asalariados, según nivel educacional. Fuente: Henríquez y Riquelme (2010)

$$
a_{i t}=\alpha_{i}+X_{i t}^{\prime} \beta^{g}+\varepsilon_{i t}
$$

donde $\beta^{g}$ es un vector de los coeficientes por género de los factores variables en el tiempo. Se asume que $\varepsilon_{i t}$ tiene media cero para cada individuo en cada período.

Todo esto implica un modelo de salario de la forma:

$$
w_{i j t}=\alpha_{i}+\psi_{j}^{g}+X_{i t}^{\prime} \beta^{g}+r_{i j t}
$$

donde $\psi_{j}^{g} \equiv \gamma^{g} \bar{S}_{j}$ y $r_{i j t}=\gamma^{g} v_{j t}+\gamma^{g} m_{i j}+\epsilon_{i t}$, que es el componente de error.

Para estimar la ecuación (4) se necesitan tres condiciones: i) $E\left[r_{i j t} X_{i t} \mid g\right]=0$ para todo género $g$, ii) $E\left[r_{i j t} \mid i\right]=0$ para todo trabajador $i$, y iii) $E\left[r_{i j t} \mid j, g\right]=0$ para toda firma $j$ y género $g$. La última condición se conoce como "movilidad exógena", que se refiere a que la movilidad de los trabajadores depende solamente del efecto persona y del efecto firma, independientemente de los componentes residuales del salario. Para verificar esta última condición se utilizará una metodología usada en Card, Heining y Kline (2013a), que será explicada en la sección 4.2 .

Con esta especificación se llega a un modelo salarial con dos efectos fijos: efecto empresa $\left(\psi_{j}^{g}\right)$ y efecto trabajador $\left(\alpha_{i}\right)$, que serán estimados separadamentes.

El efecto fijo empresa $\left(\psi_{j}^{g}\right)$ representa un premio de la empresa hacia el trabajador, es decir, la cantidad que el individuo $i$ puede extraer de la utilidad de la empresa $j$.

Las ventajas que tiene un modelo de efecto fijo es que permite controlar por heterogeneidad individual no observable y por variables omitidas en el tiempo.

Para comprobar que el poder de negociación afecta a la brecha salarial de género se debe cumplir la siguiente relación entre el efecto empresa por trabajador masculino y femenino de la firma $j$ :

$$
\psi_{j}^{F}=\left(\gamma^{F} / \gamma^{M}\right) \psi_{j}^{M}
$$

En particular, si la mujer obtiene una proporción menor de las ganancias, el efecto firma de la mujer será proporcional al efecto firma de los hombres con un factor proprocional $\gamma^{F} / \gamma^{M}<1$. Esto tiene un número de implicancias testeables para la variación relativa en salarios de hombres y mujeres entre firmas.

\section{Regulación: Ley 20.348}

Para analizar si la regulación implementada el año 2009 ha tenido efecto en la brecha salarial, se utilizará la estrategia de diferencia en diferencia. Para esto agregamos al modelo construido dos variables dummies que permitan identificar al grupo y el período del tratamiento. El grupo de tratamiento son mujeres que estén activamente trabajando en firmas con más de diez empleados contratados y el período del tratamiento es después de julio de 2009, que fue cuando se implementó la Ley 20.348. La ecuación salarial quedaría:

$w_{i j t}=\alpha_{i}+\psi_{j}^{g}+X_{i t}^{\prime} \beta^{g}+r_{i j t}+\tau d_{\text {post }}+\beta d_{\text {tratados }}+\pi d_{\text {tratados }} d_{\text {post }}$

donde $\pi$ es la variable de interés que representa el efecto de tratamiento sobre el grupo tratado, es decir, mujeres que hayan estado trabajando después de julio del año 2009. 


\section{Movilidad endógena}

Como plantea Card, Cardoso y Kline (2013a), una preocupación de este tipo de modelos (4) es que al estimarlos por OLS puede ser que los componentes residuales del salario estén correlacionados con patrones específicos de movilidad laboral, llevando a un sesgo en las estimaciones del efecto empleador y del efecto firma.

Es posible evaluar empíricamente si es que hay movilidad endógena a través de una serie de diagnósticos indirectos de especificación. El término $r_{i t}$ de la ecuación (4) contiene tres componentes. Cada uno de estos componentes está potencialmente correlacionado con el salario recibido por un trabajador, lo que podría llevar a un sesgo en el efecto firma estimado.

Cuando se está en transición al equilibrio en el proceso de asignación de trabajo en el mercado laboral, puede ocurrir una tendencia donde las personas que observan que su salario alternativo va disminuyendo se muevan a firmas de menor calidad dado que en este tipo de firmas pueden tener un mayor poder de negociación, mientras que aquellos a los que les aumenta el salario tienden a ascender a empresas de mejor calidad. Esta forma de movilidad llevaría a una caída prevista de los salarios antes de un traslado a una empresa de menor calidad y el aumento previsto de los salarios antes de un traslado a una firma de mayor calidad, que llevaría a un sesgo en la estimación del efecto firma.

Al analizar los datos, este tipo de sesgo no se encuentra en este caso. Al observar las Figuras 3 y 4 , no se ve un aumento o disminución de salario previo al moverse a una mejor o peor empresa. Más bien los perfiles salariales de diferentes grupos de destino son aproximadamente paralelos antes y después del movimiento. Esto sugiere que no hay un gran componente persistente de los salarios que se correlacione con la dirección de la movilidad de firma a firma.

De la misma forma, si hubiera un componente de la evolución de la rentabilidad de la empresa correlacionado con la dirección de la movilidad de los trabajadores que dejan la empresa, las estimaciones para el efecto firma estarían sesgadas. La presencia de estos componentes daría diferentes tendencias de los salarios antes de un movimiento de un trabajador a una firma de mejor o peor sueldo. Dada la ausencia de estas tendencias en las Figuras 3 y 4 se cree, al igual que en Card, Heining y Kline (2013b), que el componente del error del salario asociado con las fluctuaciones, $\gamma^{g} v_{j t}$, es pequeño.

Por último, la correlación que puede existir en- tre la movilidad y los componentes idiosincráticos $\left(\gamma^{g} m_{i j}\right)$ no es tan alta. Hay una cercana simetría entre trabajadores que se mueven a firmas de peor o mejor calidad, lo que sugiere que los componentes idiosincráticos laborales de los salarios no son un motivo importante de movilidad. Esto se ve en el cambio salarial ajustado: los empleados que se mueven a cuartiles más bajos tienen una disminución en el salario; en cambio, los que se mueven a firmas de mejor calidad tienen un aumento en su salario. Por ejemplo, el cambio relativo en el salario para una mujer que trabaja inicialmente en una firma del cuartil 2 y pasa al cuartil 4 es de $10 \%$ en promedio; en cambio, para un trabajador que se muda en dirección opuesta su cambio de sueldo es de $-8 \%$.

\section{Normalización efecto firma}

El modelo (4) incluye el efecto persona $\left(\alpha_{i}\right)$, el efecto firma por cada género $\left(\psi_{j}^{g}\right)$ y un conjunto de variables observables para hombres y mujeres $\left(X_{i t}^{\prime} \beta^{g}\right)$. Estos efectos se calculan en una submuestra denominada el conjunto más grande conectado de firmas que contratan hombres y mujeres ${ }^{5}$. Esto permite identificar los efectos firma y trabajador para cada género, sujeto a una normalización para cada grupo.

En el modelo se quiere comparar los efectos firma de hombres y mujeres y para esto se necesita imponer una normalización común a los dos grupos para que dichos efectos estén medidos a una misma escala. Para esto se utilizará la misma metodología utilizada en Card, Cardoso y Kline (2013a).

Este modelo sugiere que si la firma $j_{0}$ tiene una ganancia alta y contrata a ambos géneros, las mujeres serán peor pagadas que los hombres dado que $\gamma^{F}<\gamma^{M}$

$\mathrm{Al}$ calcular la diferencia entre los efectos firma de hombres y mujeres respecto de la empresa $j_{0}$, se tenderá a subestimar la verdadera medida en que las mujeres son peor pagadas. Para enfrentar este problema, los autores buscan el grupo de empresas de menores ganancias porque pagan un salario muy cercano al salario alternativo $a_{i t}$ dado que $S_{i j t}$ es muy pequeño y por ende $\gamma^{g} S_{i j t}=\psi_{j}^{g} \approx 0$.

Para normalizar se clasifican a todas las empresas en veinte grupos según su calidad de acuerdo

\footnotetext{
${ }^{5}$ Una firma está directamente conectada a otra firma si hay al menos un trabajador que es observado trabajando en ambas firmas. Una empresa está indirectamente conectada a otra si hay una secuencia de empresas directamente conectadas. El conjunto más grande conectado de firmas es el conjunto más grande de firmas que están directa o indirectamente conectadas. Ver Abowd, Creecy y Kramarz (2002).
} 
Figura 1: Perfil de salarios de trabajadores mujeres y hombres que se mueven de trabajo a partir de una firma del cuartil 1

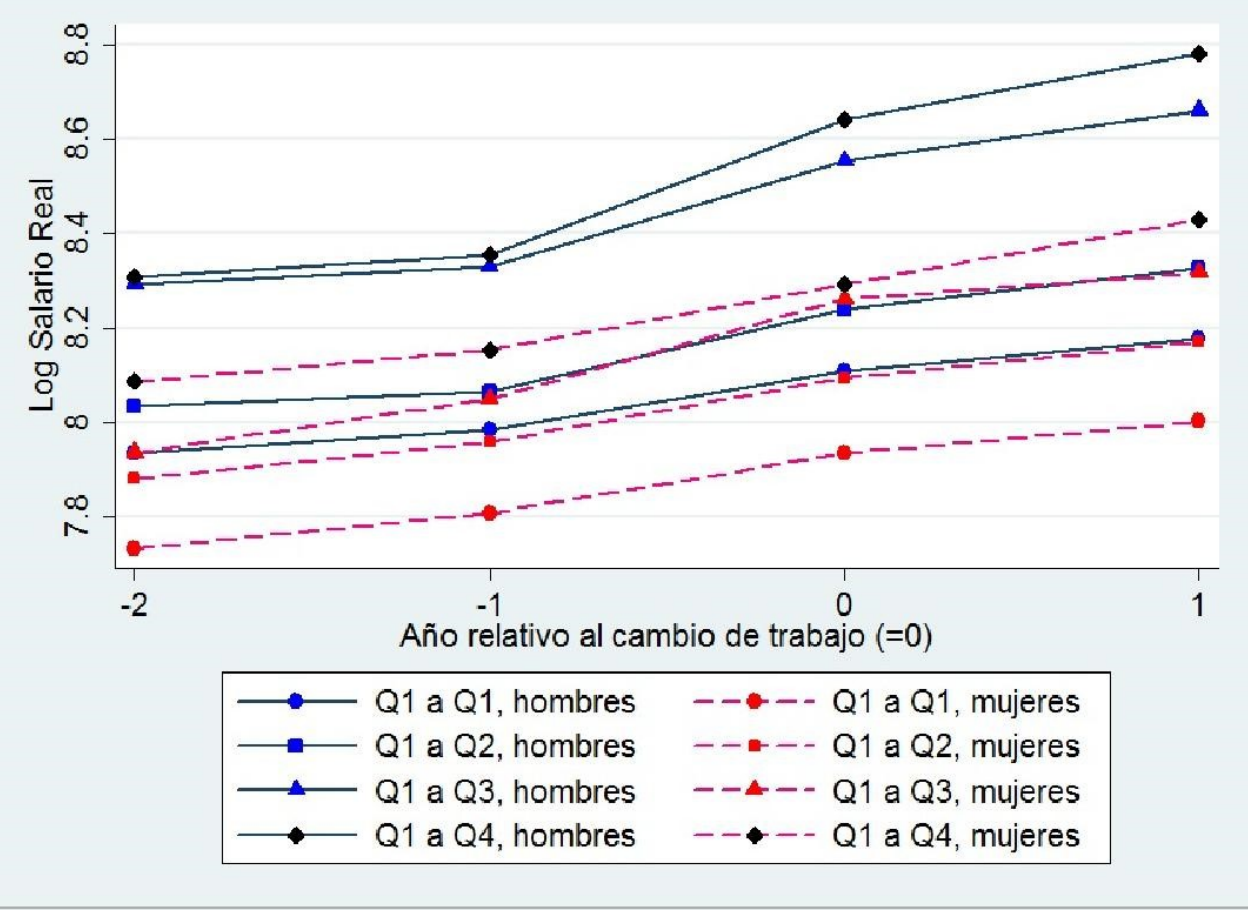

Fuente: Elaboración propia a partir de Base de datos Índices CNED 2013.

al modelo de predicción (explicado en la sección de la metodología). Se calcula el promedio del efecto firma de cada grupo y el efecto fijo del grupo de empresas de peor calidad se resta a los otros 19 grupos. El salario del "peor" grupo se acerca al salario alternativo, porque el efecto firma debería acercarse a cero.

El efecto firma normalizado se denomina $\tilde{\psi}_{j}^{g}$ y el efecto del grupo con menor ganancia es $\bar{\psi}_{0}^{g}$, por lo que el efecto firma normalizado queda:

$$
\tilde{\psi}_{j}^{g}=\psi_{j}^{g}-\bar{\psi}_{0}^{g}
$$

Haciendo el supuesto que los trabajadores de las firmas de peor calidad extraen, en promedio, cero ganancias de la utilidad de las empresas $\left(\bar{\psi}_{0}^{M}=\right.$ $\bar{\psi}_{0}^{F}=0$ ), la normalización de cada género del efecto firma queda:

$$
\tilde{\psi}_{j}^{g}=\psi_{j}^{g}=\gamma^{g} S_{j}
$$

Esto permite comparar los efectos firma entre hombres y mujeres en una escala común. En la medida que las firmas del $5 \%$ inferior paguen más a los hombres que a las mujeres, de modo que $\bar{\psi}_{0}^{M}>\bar{\psi}_{0}^{F}$, la contribución del efecto firma a la brecha salarial estará subestimada, es decir, el poder de negociación podría ser mayor al encontrado. En este caso, en el grupo de firmas de peor calidad a los hombres se les paga un $29 \%$ más que a las mujeres, lo que podría subestimar los resultados calculados en relación al poder de negociación.

\section{Datos}

Se utilizará información proveniente del sistema de Seguro de Cesantía chileno. Estos datos se componen de una muestra del $5 \%$ de los trabajadores y empleadores que fueron recopilados por la Superintendencia de Pensiones y Seguros. Todo trabajador del sector privado formal chileno está afiliado a este seguro.

Las observaciones van desde la implementación del Seguro de Cesantía, es decir, de octubre del año 2002 hasta marzo del 2013.

Al igual que en Gruetter y Lalive (2009), la muestra será limitada a empleados entre 25 y 60 años para mujeres y 65 años para hombres. Esto se debe a dos razones. Primero, la base de datos no contiene información sobre las horas trabajadas lo que no permite saber quiénes trabajan a tiempo parcial o completo. A los 25 años, la mayoría de los individuos han completado su educación, trabajando jornada completa y no a tiempo parcial. En el tramo 25 a 65 años, el porcentaje de trabajadores parciales varía entre el 6,6\% y $8 \%$. Además, el to- 
Figura 2: Perfil de salarios de trabajadores mujeres y hombres que se mueven de trabajo a partir de una firma del cuartil 4

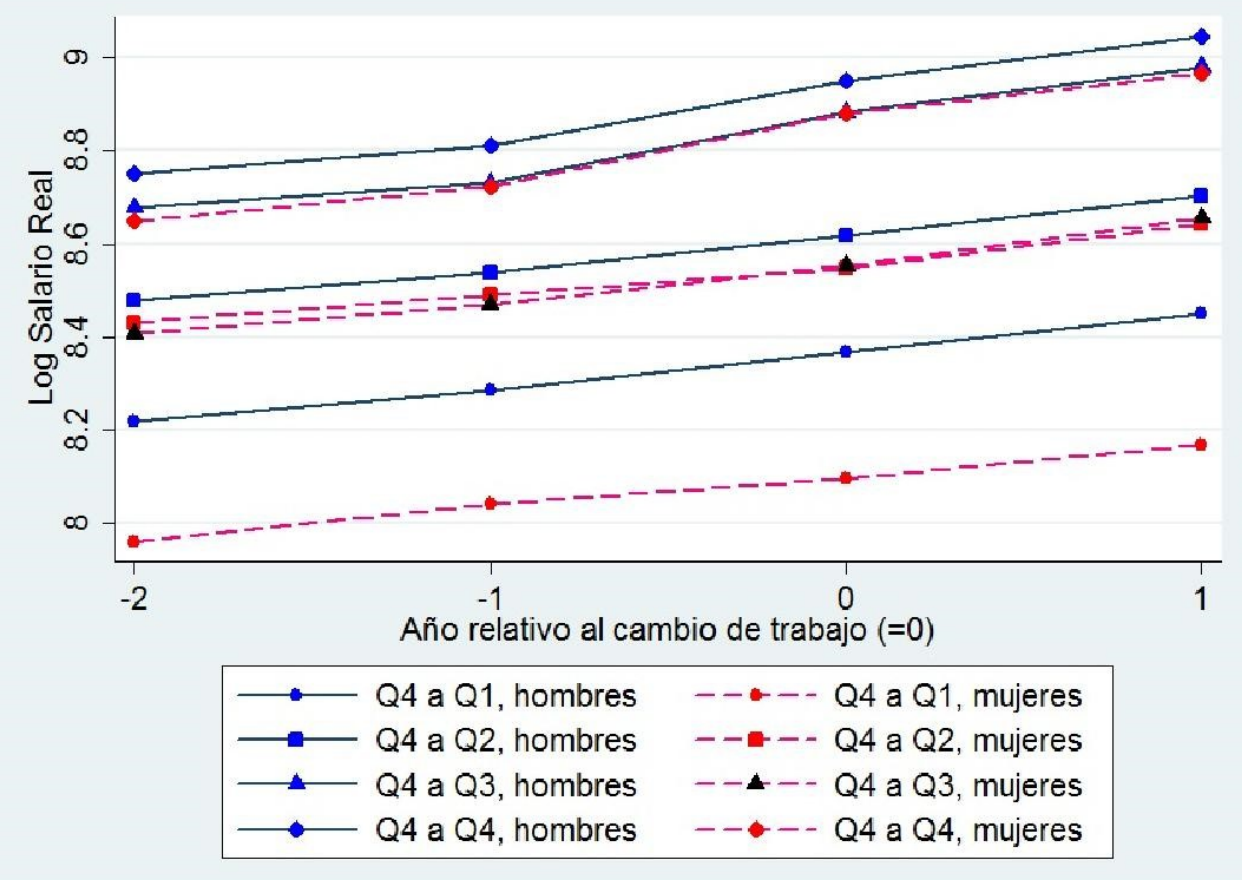

Fuente: Elaboración propia a partir de Base de datos Índices CNED 2013.

tal de trabajadores a tiempo parcial asalariados en Chile es del $9 \%$, donde el $55 \%$ son mujeres (Rau, 2010). La segunda razón es porque la edad de jubilación en Chile es a los 60 años para mujeres y 65 para hombres. En caso de múltiples trabajos en un mismo período se tomará, solo el ingreso más alto. Además, en el análisis solo se tomará en cuenta las empresas que contratan hombres y mujeres. Usando estos criterios, los datos incluyen 11.740.684 observaciones de 276.749 diferentes personas y 55.298 firmas.

Los datos de educación no están disponibles para todos los individuos dado que esta información es actualizada cada vez que el afiliado llena una solicitud de prestaciones; es decir, la persona que no ha hecho solicitudes no tiene datos de educación ${ }^{6}$.

Analizando solo a personas con datos de educación, se obtiene una base de datos que incluye 8.975.166 observaciones de 176.752 individuos y 52.946 empleadores.

Dado que se usa un modelo de efecto fijo utilizando una base panel se puede controlar por variables omitidas invariantes en el tiempo. Si la informa-

\footnotetext{
${ }^{6}$ La variable "total de años aprobados en el nivel educacional" no se tomará en cuenta dado que hay individuos sin esta información. Al calcular los años promedio de educación da 4,46 años, siendo muy por debajo de los años promedio nacionales, los que, según la Casen 2011, son de 10,50. Sin embargo, existe la información del nivel educativo de los individuos.
}

ción sobre educación de los individuos no varía en el tiempo, no debería haber problema. Los resultados al utilizar las dos muestras debieran ser similares ${ }^{7}$

\section{Principales variables}

La base de datos permite que Xit contenga las siguientes variables: experiencia, medida como la cantidad de meses trabajados en el mercado laboral; movilidad, que representa la cantidad de empresas en que ha trabajado el individuo i; nivel educativo y años estudiados.

Por el lado del empleador, incluye información sobre la comuna en que reside, el tamaño de la firma medido según la cantidad de trabajadores que tenga y la industria a la cual pertenece. Con estas variables se construye el modelo de predicción para calcular a qué cuartil de calidad pertenece cada firma.

\footnotetext{
${ }^{7} \mathrm{Al}$ realizar la regresión para calcular el poder de negociación relativo entre hombres y mujeres, los resultados son muy similares.
} 


\section{Resultados}

\section{Análisis descriptivo}

En ambas muestras las mujeres son relativamente más jóvenes que los hombres. Sin embargo, las mujeres tienen más educación que los hombres (ver Cuadro 3). El porcentaje de mujeres con educación superior y media es aproximadamente $4 \%$ mayor al de los hombres. La brecha salarial en la muestra completa es de un $23 \%$, mientras que en la muestra con datos de educación sube a $26 \%$.

Asimismo, más del $60 \%$ de los individuos trabaja en la Región Metropolitana y se observa que trabajar en esta Región tiene un efecto positivo y significativo sobre el ingreso. En promedio, las firmas tienen más empleados hombres que mujeres, en una proporción de tres hombres por cada mujer aproximadamente.

Las mujeres se concentran principalmente en los sectores de comercio e inmo-biliarias. Los únicos rubros en que las mujeres son mayoría son: hoteles, finanzas, administración pública, educación y servicios sociales. En cambio, en construcción el 90,4\% de los trabajadores son hombres y en minería, donde la brecha salarial alcanza un $49 \%$, las mujeres no sobrepasan el $9 \%$. Esto sugeriría que la mujer tiene menor poder de negociación en industrias donde es minoría, provocando una mayor brecha salarial de género. En cambio, en los sectores donde la mujer es mayoría podría tener un mayor poder de negociación, lo que se traduciría en una menor brecha. Por ejemplo, en el cuadro 4 se observa que las mujeres son mayoría en los sectores de educación y servicios sociales y de salud, donde la brecha salarial es del $5 \%$ y $3 \%$, respectivamente.

En todas las industrias los hombres ganan más que las mujeres. Los sectores donde existe una mayor diferencia salarial son las actividades de minería y manufactureras no metálicas, superando el $37 \%$. Por otro lado, la brecha salarial es bastante pequeña en los sectores de manufacturas metálicas, educación y servicios sociales, donde la diferencia es menor a $10 \%$.

Usando la información del Cuadro 3, las Figuras 1 y 2 muestran cómo los salarios anuales promedios de hombres y mujeres han variado en el tiempo. La Figura 1 muestra que los salarios de hombres y mujeres han tenido la misma tendencia, es decir, han aumentado todos los años, aunque no en la misma proporción. Esto se ve más claramente en la Figura 2, donde se observa cómo la brecha salarial de género ha variado entre los años 2002 y 2013. Entre los años 2002 y 2011 la brecha ha variado entre $24 \%$ y $26 \%$ y a partir del año 2012 la brecha aumentó considerablemente, llegando a un $29 \%$ en el año 2013.

\section{Movilidad de trabajo}

Los trabajadores en promedio están experimentando un cierto crecimiento en el salario. Al cambiar de firma se observa que la pendiente va aumentando al pasar a empresas de mayor calidad, es decir, la pendiente, de pasar de Q1 a Q4, es mayor que de pasar de Q1 a Q2. Además, en todos los perfiles se observa que las mujeres se encuentran por debajo del ingreso masculino, lo que refleja una existencia de una brecha salarial de género. En el Cuadro 5 se presenta mayor detalle sobre información de los salarios antes y después del cambio de trabajo de hombres y mujeres separados en 16 grupos. Por ejemplo, se denota el movimiento del cuartil 1 al cuartil 2 como "Q1 a Q2".

Para cada grupo de origen-destino se muestra el cambio de salario comparando el sueldo promedio recibido el último año en la empresa antigua y el pago del primer año en la firma nueva bajo el nombre de cambio salarial al cambiarse. También se incluye la variable cambio salarial ajustado, que es el cambio salarial de los trabajadores en los diferentes grupos restado por el cambio de salario para los trabajadores que cambian de empleo, pero que permanecen en el mismo cuartil de origen. Además, se muestra el número de observaciones en cada grupo origen-destino y el porcentaje de trabajadores que se mueven de un cuartil a otro en cada grupo.

Viendo el cambio salarial ajustado en el Cuadro 4, se confirma que el trabajador que se mueve a una firma de mayor calidad recibe un aumento en su salario; lo contrario ocurre si se cambia a un cuartil más bajo.

En la mayoría de estos casos, se observa una pérdida y una ganancia a veces aproximadamente simétricas. Por ejemplo, el cambio relativo en el salario para un trabajador hombre que trabaja inicialmente en una firma del cuartil 1 y pasa al cuartil 2 es de $3 \%$ en promedio; en cambio, para un trabajador que hace el cambio en dirección opuesta su cambio de sueldo es de $-3 \%$. Esta simetría de las pérdidas y ganancias por la movilidad en direcciones opuestas es predicha por el modelo especificado por las ecuaciones (5) y (6), que asume que la movilidad es independiente de componentes específicos de cada trabajador en cada firma.

Al observar el Cuadro 4, no es claro si las mujeres tienen un aumento salarial más bajo que los hombres al cambiarse de trabajo. A veces los hombres 
Cuadro 2: Análisis descriptivo

\begin{tabular}{|c|c|c|c|c|c|c|}
\hline & \multicolumn{3}{|c|}{ MUESTRA COMPLETA } & \multirow{2}{*}{ MUESTRA CON } & \multicolumn{2}{|c|}{ DATOS DE EDUCACIÓN } \\
\hline & Hombres & Mujer & Total & & Mujeres & Total \\
\hline Porcentaje & $62,5 \%$ & $37,5 \%$ & $100 \%$ & $65,8 \%$ & $34,2 \%$ & $100 \%$ \\
\hline Edad & & & & & & \\
\hline Promedio & 40,4 & 38,5 & 39,7 & 40,4 & 38,6 & 39,8 \\
\hline Mayores 50 años & $18,5 \%$ & $12,2 \%$ & $16,2 \%$ & $18,3 \%$ & $12,5 \%$ & $16,3 \%$ \\
\hline Menores 30 años & $15,6 \%$ & $18,5 \%$ & $16,7 \%$ & $15,2 \%$ & $17,7 \%$ & $16,2 \%$ \\
\hline Educación & & & & & & \\
\hline Sin educación & & & & $9,3 \%$ & $6,7 \%$ & $8,4 \%$ \\
\hline Ed. básica & & & & $33,8 \%$ & $27,9 \%$ & $31,8 \%$ \\
\hline Ed. media & & & & $47,4 \%$ & $52,1 \%$ & $49,0 \%$ \\
\hline Ed. superior & & & & $9,5 \%$ & $13,3 \%$ & $10,8 \%$ \\
\hline Salario real promedio & 8,12 & 7,89 & 8,04 & 8,07 & 7,81 & 7,98 \\
\hline Porcentaje en santiago & $60,6 \%$ & $62,0 \%$ & $61,1 \%$ & $59,5 \%$ & $60,4 \%$ & $59,8 \%$ \\
\hline Tamaño promedio firma & 14,9 & 8,7 & 23,6 & 15,5 & 9,1 & 24,6 \\
\hline Porcentaje por firma & $63,1 \%$ & $36,9 \%$ & $100 \%$ & $63,0 \%$ & $37,0 \%$ & $100 \%$ \\
\hline Número de observaciones & 7.336 .899 & 4.403 .785 & 11.740 .684 & 5.901 .313 & 3.073 .853 & 8.975 .166 \\
\hline Número de empleados totales & 159.853 & 116.896 & 276.749 & 111.994 & 64.758 & 176.752 \\
\hline Cantidad de firmas & & & 55.298 & & & 52.946 \\
\hline
\end{tabular}

Cuadro 3: Análisis descriptivo por industria

\begin{tabular}{|c|c|c|c|c|c|c|c|}
\hline Industria & $\begin{array}{c}\text { Distribución de } \\
\text { mujeres en } \\
\text { las industrias }\end{array}$ & $\begin{array}{c}\text { Distribución de } \\
\text { hombres en } \\
\text { las industrias }\end{array}$ & $\begin{array}{c}\text { Mujeres } \\
\text { por industria }\end{array}$ & $\begin{array}{c}\text { Hombres } \\
\text { por industria }\end{array}$ & $\begin{array}{l}\text { Ingreso promedio } \\
\text { por industria } \\
\text { Mujeres }\end{array}$ & $\begin{array}{c}\text { Ingreso promedio } \\
\text { por industria } \\
\text { Hombres }\end{array}$ & Brecha salarial \\
\hline Todas las industrias & 100,0 & 100,0 & & & & & \\
\hline Agricultura & 7,4 & 7,9 & 36,1 & 63,9 & 7,28 & 7,58 & 0,30 \\
\hline Pesca & 0,7 & 0,9 & 32,8 & 67,2 & 7,91 & 8,24 & 0,33 \\
\hline Minería & 0,6 & 1,9 & 15,1 & 84,9 & 8,57 & 9,06 & 0,49 \\
\hline Manufactureras no metálicos & 7,8 & 8,8 & 34,8 & 65,2 & 7,86 & 8,23 & 0,37 \\
\hline Manufactureras metálicas & 1,2 & 3,3 & 17,7 & 82,3 & 8,22 & 8,31 & 0,09 \\
\hline Electricidad, gas y agua & 0,3 & 0,5 & 22,0 & 78,0 & 8,73 & 8,85 & 0,12 \\
\hline Construcción & 3,5 & 19,7 & 9,6 & 90,4 & 7,90 & 8,10 & 0,20 \\
\hline Comercio al por mayor y menor & 19,3 & 14,3 & 44,7 & 53,3 & 7,83 & 8,15 & 0,32 \\
\hline Hoteles y restaurantes & 5,5 & 2,9 & 52,7 & 47,3 & 7,60 & 7,82 & 0,22 \\
\hline Transporte y comunicaciones & 4,2 & 7,7 & 24,9 & 75,1 & 8,15 & 8,25 & 0,10 \\
\hline Finanzas & 6,3 & 3,2 & 54,2 & 45,8 & 8,54 & 8,65 & 0,11 \\
\hline Inmobiliarias & 16,9 & 16,0 & 38,8 & 61,2 & 7,84 & 8,09 & 0,25 \\
\hline Administración pública & 4,9 & 2,2 & 56,8 & 43,2 & 7,69 & 7,82 & 0,13 \\
\hline Enseñanza & 7,7 & 3,2 & 59,4 & 40,6 & 8,27 & 8,32 & 0,05 \\
\hline Servicios sociales y de salud & 3,2 & 0,9 & 66,8 & 33,2 & 8,26 & 8,29 & 0,03 \\
\hline Servicios comunitarios & 8,6 & 5,2 & 49,9 & 50,1 & 7,75 & 7,93 & 0,18 \\
\hline Edificios y condominios & 0,1 & 0,1 & 41,2 & 58,8 & 7,64 & 7,77 & 0,13 \\
\hline
\end{tabular}

reciben un mayor aumento salarial que las mujeres, pero en otros casos los sueldos son muy similares.

La Figura 5 ayuda a entender qué pasa con los cambios salariales. En ella se grafica el cambio salarial de las mujeres en cada uno de los 16 grupos de origen-destino en comparación al cambio de sueldo de los hombres. La mayoría de los puntos están muy cerca o por debajo de la línea de 45 grados. Además, se realiza una regresión ${ }^{8}$ para estimar la pendiente que relacione el cambio salarial entre hombres y mujeres.

En los 16 grupos de origen-destino se observa la pendiente que relaciona el cambio salarial de hombres y mujeres (curva sólida en la Figura 5). Al realizar la regresión, el valor de la pendiente es de 0,83 con una confianza del $99 \%$ con un intervalo de

\footnotetext{
${ }^{8} \Delta w_{i t}^{F}\left(j_{t-1}, j_{t}\right)=\beta \Delta w_{i t}^{M}\left(j_{t-1}, j_{t}\right)+\alpha$ donde $\beta=$ $\gamma^{F} / \gamma^{M}$ y debería ser menor a 1 .
}

0,40 a 1,27. Esto muestra que los hombres se benefician más al cambiarse de trabajo que las mujeres $\left(\gamma^{F} / \gamma^{M}=83 \%\right)$. Por ejemplo, si los hombres al cambiarse de firma logran aumentar su salario en mil pesos, las mujeres al realizar el mismo cambio de trabajo solo logran aumentar en 830 pesos su sueldo.

Al comparar este resultado con los obtenidos por Card, Cardoso y Kline (2013a), se ven pequeñas diferencias. En Portugal, se observa que no hay mucha diferencia entre hombres y mujeres en el caso no ajustado $\left(\gamma^{F} / \gamma^{M}=96 \%\right)$.

La Figura 6 grafica exactamente lo mismo para el caso del cambio de salario ajustado. En este caso se tiene 12 grupos para realizar la regresión donde se obtiene una pendiente de $95 \%$, con una significancia al $99 \%$ y con un intervalo de 0,55 a 1,36 . Esto indica que las mujeres aumentan su salario apro- 
Figura 3: Diferencia salarial

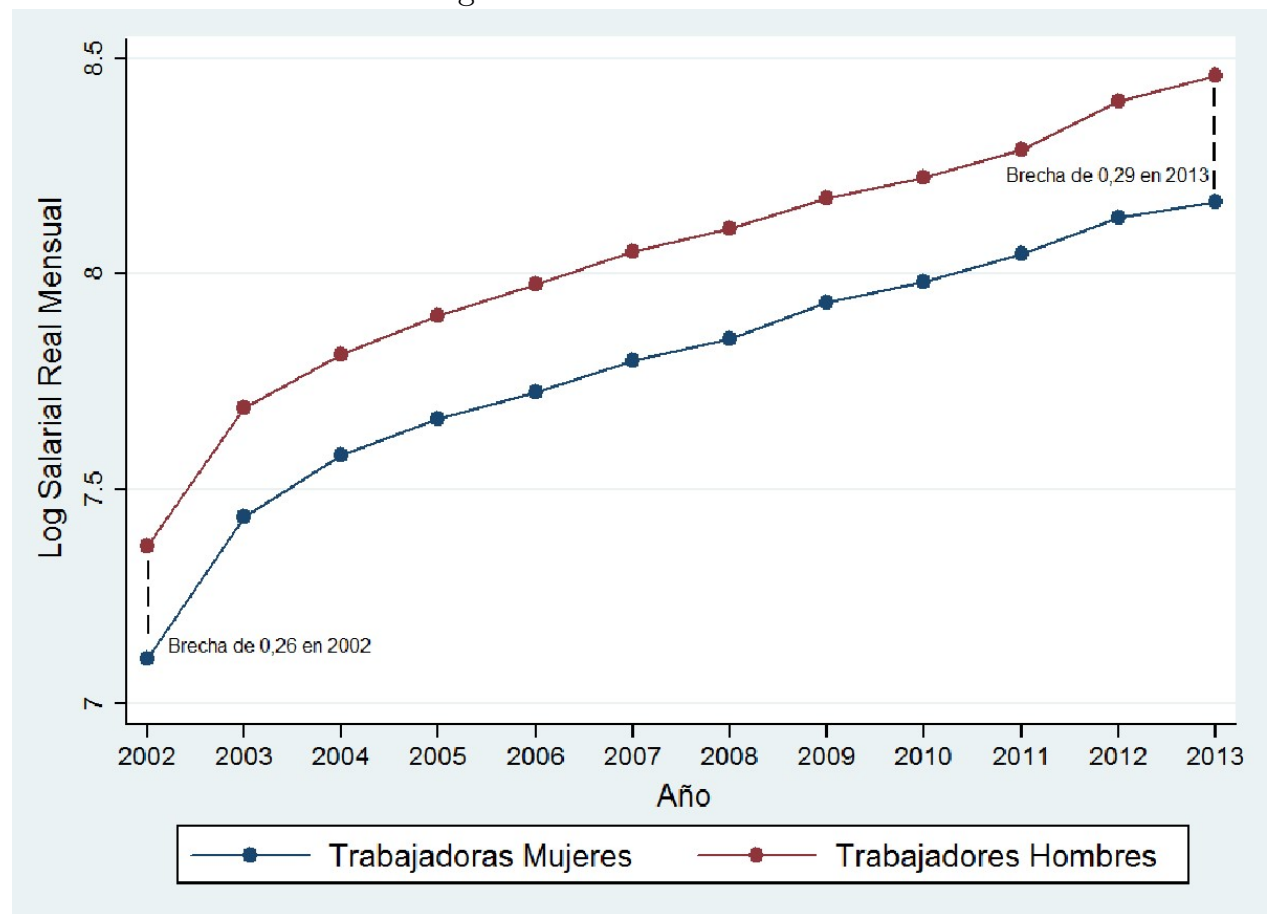

Fuente: Elaboración propia a partir de la base de datos del Seguro de Cesantía.

ximadamente un $5 \%$ menos, en promedio, que los hombres al cambiarse de firma.

Estos resultados indican que la mujer tiene menor poder de negociación que el hombre al cambiarse de trabajo. Esto coincide con el estudio de Rigdon (2012) y Bowles et al. (2005), que sostiene que la mujer tiene menor poder de negociación al iniciar un nuevo empleo dado que piden menos salario inicial, lo que implica que su aumento salarial al cambiarse de trabajo en comparación a los hombres sea menor.

Otro dato interesante que se ve en el Cuadro 4 es que el porcentaje de hombres y mujeres que se mueven de un grupo de origen a un cuartil de destino es relativamente parecido. En el caso de individuos que inicialmente trabajan en una firma del cuartil 4 , el $6 \%$ aproximadamente se cambia a una firma del primer cuartil, mientras que el $64,8 \%$ de los hombres y el $67,4 \%$ de las mujeres se mantienen en el cuarto cuartil. Esto puede sugerir que el proceso de movilidad de hombres y mujeres es bastante similar en el mercado laboral chileno.

\section{Efecto firma}

Para obtener los efectos firma se utilizó el comando para stata basado en la metodología de Abowd, Creecy, Kramarz (2002) creado por Ouzad (2008).
El Cuadro 6 resume los parámetros estimados para el modelo de hombres y mujeres entre los años 2002 y 2013. Estos modelos incluyen los efectos fijos para firmas e individuos.

Todos los datos son mensuales y se hicieron dummies anuales que interactúan con dummies de educación (básica, media y universitaria) y las variables edad cúbica y cuadrática, que interactúan con las dummies de educación. Para el caso de la muestra sin educación se usan dummies de años y de edad. El Cuadro 5 muestra los efectos firma y persona, la correlación entre ambos efectos, la desviación estándar residual del modelo y el $\mathrm{R}$-cuadrado ajustado.

Para hombres y mujeres, el efecto persona es mayor que el efecto firma en ambos casos. Esto quiere decir que una parte relativamente grande de la desigualdad salarial entre géneros es atribuible a las diferencias permanentes en las características de los diferentes trabajadores. En comparación con los resultados de Portugal, en Chile el efecto firma tiene un tercio más de importancia. Esto indica que en Chile el efecto firma podría tener una mayor incidencia en la brecha salarial.

La correlación entre los efectos firma y persona no tiene mucha diferencia con el estudio de Card, Cardoso y Kline (2013a). En ambos casos son positivos, lo que implica que los hombres y las mujeres con mayores habilidades se emplean en las firmas que pagan mayores salarios a todos sus trabajado- 
Figura 4: Variación de brecha salarial en el tiempo

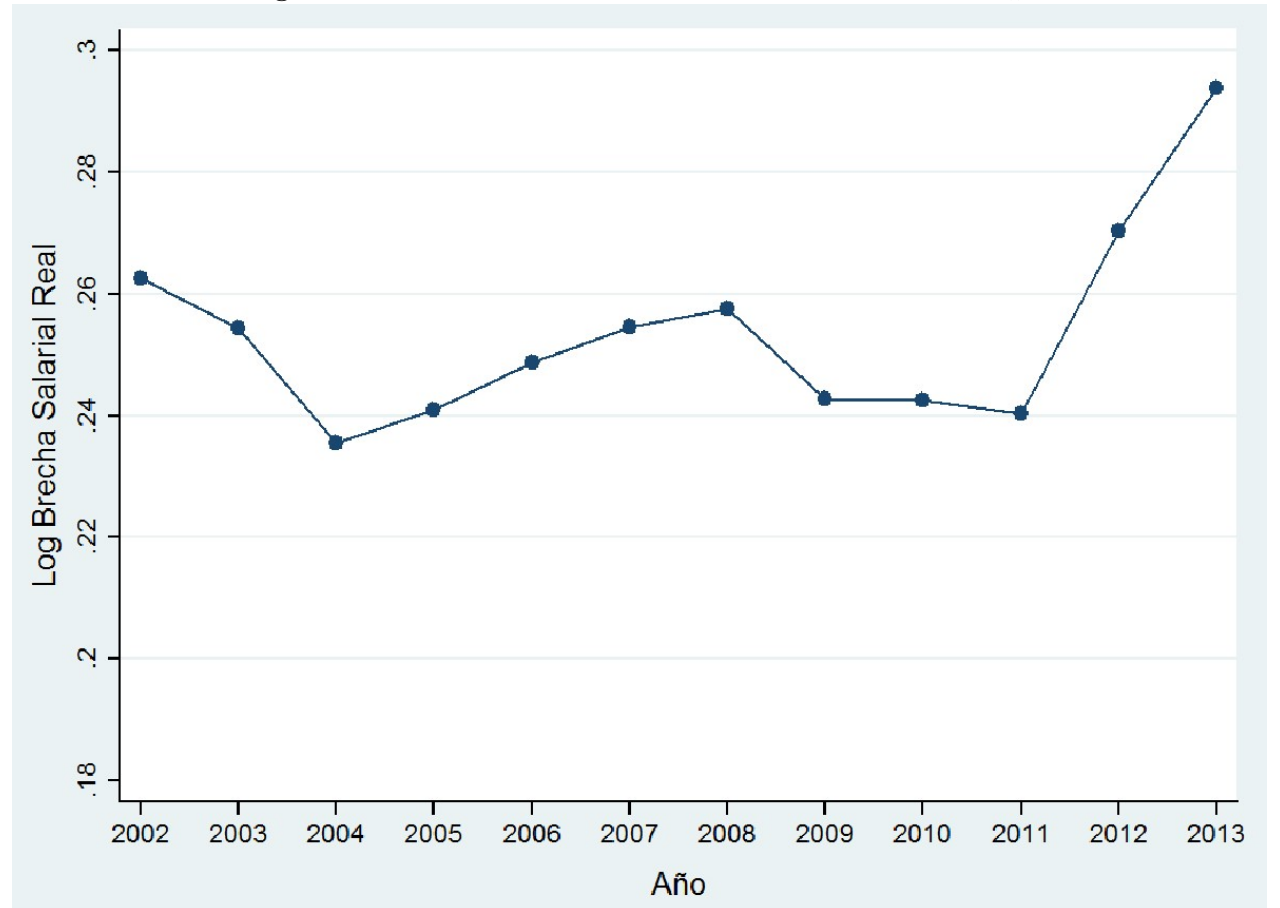

Fuente: Elaboración propia a partir de la base de datos del Seguro de Cesantía.

res.

Por otro lado, al final del Cuadro 5 se observa la descomposición de la varianza del salario para trabajadores que se presenta en la ecuación (4):

$$
\begin{gathered}
\operatorname{Var}\left(w_{i t}\right)= \\
\operatorname{Var}\left(\hat{\alpha}_{i}\right)+\operatorname{Var}\left(\hat{\psi}_{j}{ }^{g}\right)+2 \operatorname{Cov}\left(\hat{\alpha}_{i}, \hat{\psi}_{j}{ }^{g}\right)+\operatorname{Var}\left(X_{i t}^{\prime} \hat{\beta}^{g}\right) \\
+\operatorname{Var}\left(\hat{r}_{i t}\right)+2 \operatorname{Cov}\left(\hat{\alpha}_{i}+\hat{\psi}_{j}{ }^{g}, X_{i t}^{\prime} \hat{\beta}^{g}\right)
\end{gathered}
$$

Se observa que para hombres y mujeres el efecto persona explica aproximada-mente el $30 \%$ de la variación global del salario, el efecto firma alrededor del $20 \%$ y la covarianza entre los efectos firma y persona representa un $2 \%$ aproximadamente. La varianza de los regresores, $X_{i t}^{\prime} \hat{\beta}^{g}$, representa un $10 \%$ de la varianza total. Algo muy importante que notar es que la varianza de los residuos es relativamente alta $(30 \%)$. Esto indica que puede haber variables que no estén en el modelo, que pueden explicar el salario y que en este caso se encuentran en el error. Sin embargo, la varianza del error es $4 \%$ más pequeña en la muestra sin datos de educación que en la con educación, lo cual se ve reflejado en el $\mathrm{R}$-cuadrado. Esto se puede deber a que la muestra sin educación aporta mayor información dado que tiene más observaciones que la otra muestra. Por otro lado, el efecto firma tiene una mayor varianza en los resultados con datos de educación; es decir, el efecto firma explica un mayor porcentaje en este $\operatorname{caso}^{9}$

Por último, en las Figuras 7 y 8 se hace una especificación adicional del modelo para hombres y mujeres basado en la ecuación (4) para ver si es una buena aproximación a la fijación de salarios en Chile, al igual que en Card, Cardoso y Kline (2013a). Para esto, se clasificaron en 10 grupos de igual tamaño los efectos persona y firma separadamente. Luego, se calculó los promedios residuales del modelo (rit) de cada grupo. Con esto se obtuvieron 100 celdas de los residuos del modelo separadamente.

En las figuras se observa que los residuos en las 100 celdas son muy pequeños para ambos géneros. En cada una de estas celdas, el promedio de los residuos en valor absoluto es menor a 0,03. Esto sugiere que la estructura de la ecuación (4) es un buen modelo, dado el bajo error que tiene.

\section{Brecha salarial de género}

Como se menciona en Card, Cardoso y Kline (2013a), es difícil demostrar la diferencia salarial entre hombres y mujeres mirando una empresa en particular dado que los efectos firma son medidos con error. Sin embargo, normalizando y agrupando firmas se pueden comparar los efectos firma prome-

\footnotetext{
${ }^{9}$ Se tomará en cuenta en el análisis que viene la muestra con datos de educación, dado que el efecto firma explica un mayor porcentaje del modelo.
} 
Cuadro 4: Salario promedio de movilidad de trabajadores antes y después del cambio, por origen y destino según cuartil de calidad.

\begin{tabular}{|c|c|c|c|c|c|c|c|c|}
\hline & \multicolumn{8}{|c|}{ Cambio de Trabajo Masculino } \\
\hline & (1) & $(2)$ & (3) & (4) & $(1)$ & $(2)$ & (3) & (4) \\
\hline & Q1 a Q1 & Q1 a Q2 & QQ1 a Q3 & Q1 a Q4 & Q1 a Q1 & Q1 a Q2 & QQ1 a Q3 & Q1 a Q4 \\
\hline Salario real promedio: & & & & & & & & \\
\hline 2 años antes del cambio & 7,91 & 8,01 & 8,08 & 8,23 & 7,72 & 7,84 & 8,12 & 8,06 \\
\hline 1 año antes del cambio & 7,96 & 8,06 & 8,16 & 8,29 & 7,78 & 7,92 & 8,12 & 8,12 \\
\hline Año del cambio & 8,09 & 8,24 & 8,39 & 8,52 & 7,93 & 8,06 & 8,14 & 8,25 \\
\hline$A$ un año del cambio & 8,16 & 8,32 & 8,50 & 8,65 & 7,98 & 8,14 & 8,39 & 8,41 \\
\hline Cambio salarial al cambiarse & 0,13 & 0,16 & 0,24 & 0,24 & 0,14 & 0,14 & 0,19 & 0,14 \\
\hline Cambio salarial ajustado & 0,00 & 0,03 & 0,12 & 0,11 & 0,00 & 0,00 & 0,05 & 0,00 \\
\hline Número de observaciones & 17.856 & 10.224 & 5.436 & 5.616 & 8.880 & 3.888 & 2.616 & 1.968 \\
\hline \multirow[t]{2}{*}{ Porcentaje de cambio desde cuartil de origen } & 44,6 & 26,1 & 13,9 & 14,4 & 51,2 & 22,4 & 15,1 & 11,3 \\
\hline & Q2 a Q1 & Q2 a Q2 & Q2 a Q3 & Q2 a Q4 & Q2 a Q1 & Q2 a Q2 & Q2 a Q3 & Q2 a Q4 \\
\hline \multicolumn{9}{|l|}{ Salario real promedio: } \\
\hline 2 años antes del cambio & 8,00 & 8,13 & 8,22 & 8,28 & 7,77 & 7,89 & 7,98 & 8,00 \\
\hline 1 año antes del cambio & 8,03 & 8,16 & 8,26 & 8,33 & 7,80 & 7,94 & 8,06 & 8,07 \\
\hline Año del cambio & 8,14 & 8,30 & 8,47 & 8,60 & 7,86 & 8,06 & 8,24 & 8,36 \\
\hline A un año del cambio & 8,21 & 8,39 & 8,57 & 8,74 & 7,94 & 8,12 & 8,38 & 8,49 \\
\hline Cambio salarial al cambiarse & 0,10 & 0,14 & 0,22 & 0,28 & 0,06 & 0,11 & 0,18 & 0,29 \\
\hline Cambio salarial ajustado & $-0,03$ & 0,00 & 0,08 & 0,14 & $-0,05$ & 0,00 & 0,07 & 0,18 \\
\hline Número de observaciones & 8.448 & 21.420 & 7.584 & 11.244 & 3.648 & 11.676 & 4.464 & 5.604 \\
\hline \multirow{2}{*}{ Porcentaje de cambio desde cuartil de origen } & 17,3 & 44,0 & 15,6 & 23,1 & 14,4 & 46,0 & 17,6 & 22,1 \\
\hline & Q3 a Q1 & Q3 a Q2 & Q3 a Q3 & Q3 a Q4 & Q3 a Q1 & Q3 a Q2 & Q3 a Q3 & Q3 a Q4 \\
\hline \multicolumn{9}{|l|}{ Salario real promedio: } \\
\hline 2 años antes del cambio & 8,20 & 8,16 & 8,46 & 8,39 & 7,85 & 7,85 & 8,24 & 8,04 \\
\hline 1 año antes del cambio & 8,26 & 8,22 & 8,50 & 8,47 & 7,90 & 7,93 & 8,32 & 8,10 \\
\hline Año del cambio & 8,37 & 8,28 & 8,62 & 8,66 & 8,04 & 8,00 & 8,48 & 8,34 \\
\hline A un año del cambio & 8,44 & 8,40 & 8,70 & 8,79 & 8,11 & 8,08 & 8,55 & 8,44 \\
\hline Cambio salarial al cambiarse & 0,11 & 0,06 & 0,12 & 0,19 & 0,14 & 0,07 & 0,16 & 0,24 \\
\hline Cambio salarial ajustado & $-0,01$ & $-0,06$ & 0,00 & 0,07 & $-0,01$ & $-0,09$ & 0,00 & 0,08 \\
\hline Número de observaciones & 5.532 & 8.880 & 20.172 & 14.208 & 3.408 & 7.296 & 10.380 & 7.200 \\
\hline \multirow[t]{2}{*}{ Porcentaje de cambio desde cuartil de origen } & 11,3 & 18,2 & 41,3 & 29,1 & 12,0 & 25,8 & 36,7 & 25,5 \\
\hline & Q4 a Q1 & Q4 a Q2 & Q4 a Q3 & Q4 a Q4 & Q4 a Q1 & Q4 a Q2 & Q4 a Q3 & Q4 a Q4 \\
\hline \multicolumn{9}{|l|}{ Salario real promedio: } \\
\hline 2 años antes del cambio & 8,23 & 8,34 & 8,54 & 8,55 & 7,91 & 8,21 & 8,39 & 8,48 \\
\hline 1 año antes del cambio & 8,27 & 8,40 & 8,59 & 8,61 & 7,98 & 8,28 & 8,46 & 8,55 \\
\hline Año del cambio & 8,35 & 8,53 & 8,75 & 8,75 & 8,03 & 8,30 & 8,60 & 8,69 \\
\hline$A$ un año del cambio & 8,45 & 8,63 & 8,86 & 8,85 & 8,12 & 8,42 & 8,69 & 8,79 \\
\hline Cambio salarial al cambiarse & 0,08 & 0,14 & 0,16 & 0,14 & 0,05 & 0,02 & 0,14 & 0,14 \\
\hline Cambio salarial ajustado & $-0,06$ & 0,00 & 0,02 & 0,00 & $-0,09$ & $-0,13$ & 0,00 & 0,00 \\
\hline Número de observaciones & 3.360 & 7.044 & 8.448 & 34.632 & 1.488 & 2.604 & 4.752 & 18.264 \\
\hline Porcentaje de cambio desde cuartil de origen & 6,3 & 13,2 & 15,8 & 64,8 & 5,5 & 9,6 & 17,5 & 67,4 \\
\hline
\end{tabular}

dio de hombres y mujeres para un grupo de empresas.

En la Figura 9 se grafica el valor promedio del efecto firma femenino (eje y) contra el valor promedio del efecto firma masculino (eje $\mathrm{x}$ ) en 20 grupos definidos por su calidad laboral, usando el modelo de predicción.

Se observa que todos los puntos se encuentran por debajo de la línea de 45 grados, lo que indica que los hombres tienen un mayor efecto fijo en todos los grupos (obtienen un mayor premio salarial). Al realizar la regresión da una pendiente igual a $79 \% 10$ , esto indica que los hombres tienen un mayor poder de negociación que las mujeres $\left(\gamma^{F} / \gamma^{M}=0,79\right)$.

Por ejemplo, si los hombres logran extraer mil pesos de la utilidad de la empresa, las mujeres solo logran obtener 790 pesos $^{11}$. La implicancia de esto indica que las mujeres logran capturar un menor premio salarial que los hombres. Esta desigualdad

\footnotetext{
${ }^{10}$ Este resultado puede estar por debajo de lo real dado que en las empresas de peor calidad les pagan más a los hombres, lo cual puede causar una subestimación al normalizar el efecto firma de cada género.

${ }^{11} \mathrm{Al}$ realizar este análisis con la muestra sin datos de educación, da un resultado del $83 \%$.
}

es más grande en Chile que en Portugal; en el país europeo da un resultado del $88 \%$.

El resultado encontrado en Chile es $9 \%$ mayor que en Portugal (Card et al., 2013a). Sin embargo, es necesario calcular cuánto afecta este resultado a la brecha salarial de género; es decir, cuánto explica el poder de negociación la diferencia salarial en Chile.

Para esto se realiza la misma metodología utilizada en Card, Cardoso y Klines (2013a) que se basa en la descomposición de Oaxaca (1973).

En el Cuadro 6 se observan los cálculos realizados. La primera fila muestra el salario promedio de hombres y mujeres, los cuales tienen una brecha salarial de 27,4 puntos logarítmicos. Las filas 2 a 5 muestran distintos contrafactuales realizados.

En la fila 2 se asigna el efecto firma (premio salarial) masculino a las mujeres en cada firma. Bajo este escenario, las mujeres incrementan su salario en 7,4 puntos logarítmicos, lo que hace que la brecha salarial caiga a 20 puntos logarítmicos. Esto indica que la capacidad de extraer renta de las mujeres respecto de los hombres explica alrededor del 
Figura 5: Cambio salarial de hombres y mujeres en el mismo cuartil de calidad de trabajo

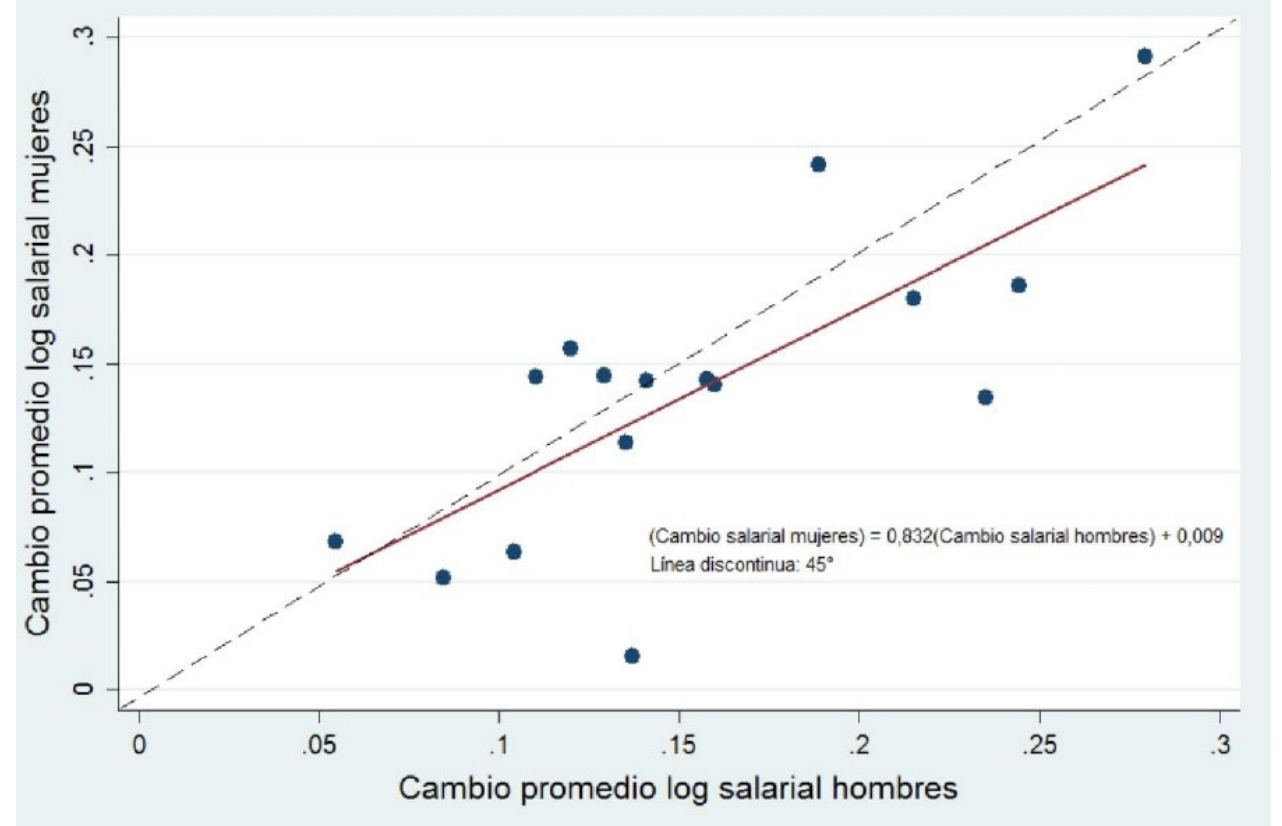

Fuente: Elaboración propia.

$27 \%$ de la brecha salarial de género.

En la fila 3 se invierte el contrafactual anterior; es decir, se asigna el efecto firma femenino a los hombres en cada empresa. En este escenario, el salario masculino cae en 7,9 puntos logarítmicos y la brecha salarial cae a 19,5 puntos logarítmicos, lo que explicaría el $29 \%$ de la diferencia salarial. Esto implica que entre el $27 \%$ y el $28 \%$ de la brecha salarial de género es atribuible a la diferencia del poder de negociación entre hombres y mujeres.

Las filas 4 y 5 consideran escenarios donde el efecto empresa se mantiene sin cambios en ambos géneros, pero se asume la misma distribución masculina para las mujeres en cada firma (fila 4) y la misma distribución femenina de cada firma para los hombres (fila 5$)^{12}$.

Asignando la distribución de los hombres a las mujeres, el salario femenino incrementa en 21,1 puntos logaritmicos, lo suficiente para explicar el $70 \%$ de la brecha salarial. Invertir el proceso y asignar la distribución de mujeres a los hombres en cada firma llevan a una disminución en el salario masculino en 11,6 puntos logarítmicos, lo que explica el $42 \%$ de la diferencia salarial de género.

De la descomposición salarial del Cuadro 6 se llega a dos principales conclusiones:

\footnotetext{
${ }^{12}$ Se redestribuye a las mujeres en cada firma por un peso que es igual al total de trabajadores hombres en cada firma dividido por el total de mujeres en cada firma. Esta técnica se discute en DiNardo, Lemieux y Fortin (1996).
}

Primero, el menor grado de extracción de utilidad de las mujeres con respecto a los hombres $(63 \%)$ ilustrado en la Figura 9 lleva a una reducción en el salario femenino entre 7,4 y 7,9 puntos porcentuales, relativo a un escenario en donde las mujeres reciben el mismo premio salarial que sus compañeros hombres en cada firma. Este efecto es grande en tamaño, suficiente para explicar el $27-28 \%$ de la brecha salarial de género en Chile. En comparación con Portugal, este resultado es mayor. En el país europeo la diferencia en el poder de negociación es del $88 \%$, lo que explica entre el 10-15\% la brecha salarial de género.

Segundo, aproximadamente el $45-75 \%{ }^{13}$ de la brecha salarial es explicada por el hecho de que las mujeres son desproporcionalmente empleadas en firmas que pagan menos salarios a ambos sexos. Este resultado concuerda con el PNUD (2010), donde se señala que en Chile las remuneraciones promedio de las profesiones descienden a medida que estas se hacen más "femeninas".

Concretamente, el $20 \%$ de las profesiones con menor porcentaje de mujeres tiene asociado un ingreso promedio de $\$ 900.000$, mientras que el $20 \%$ con mayor porcentaje de mujeres gana en promedio $\$ 400.000$. Entre las primeras se encuentran las ingenierías civiles y forestales, geología y construcción civil; entre las segundas destacan educación diferencial, educación parvularia, psicopedagogía, nu-

\footnotetext{
${ }^{13}$ Este resultado se calculó con información estimada del número de empleados mujeres y hombres en cada empresa, por lo que podría no ser exacto.
} 
Figura 6: Cambio salarial ajustado de hombres y mujeres en el mismo cuartil de calidad de trabajo

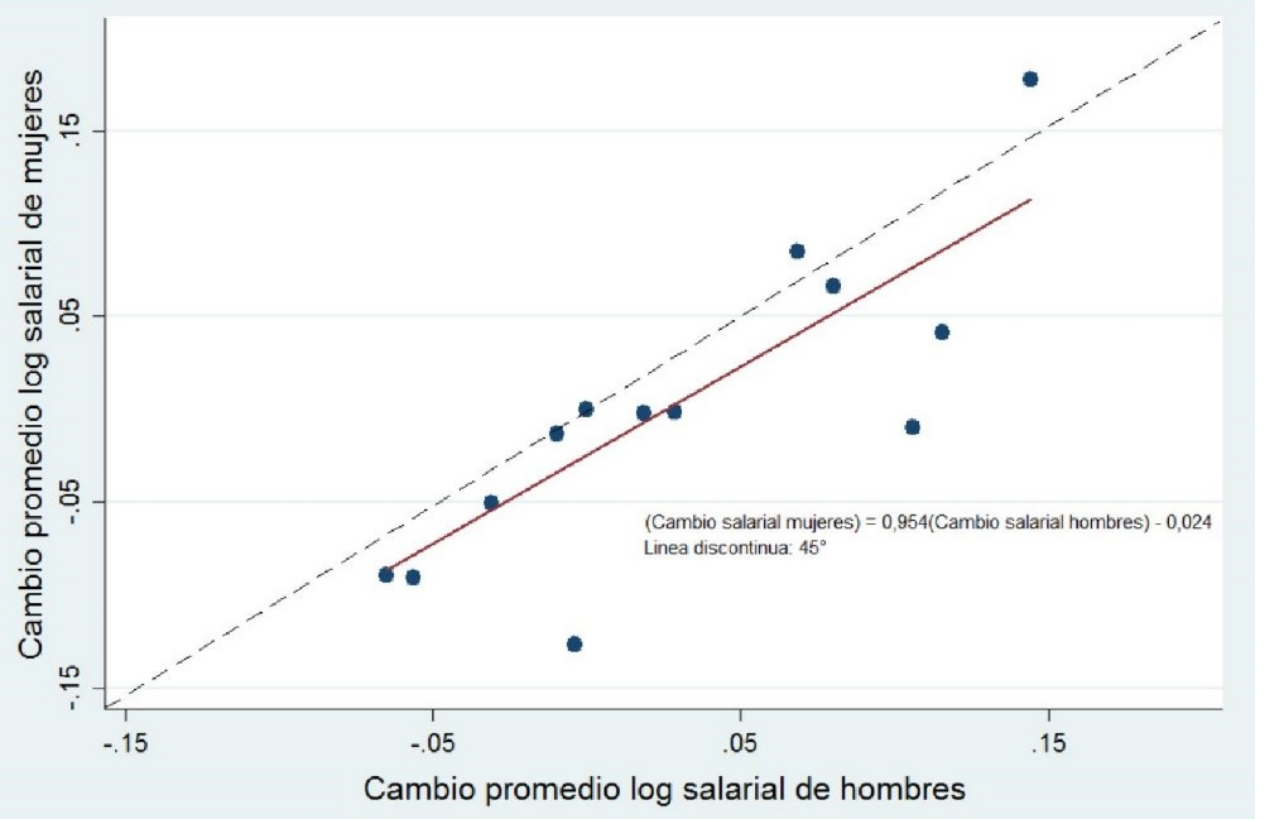

Fuente: Elaboración propia.

trición y otros similares (de las Naciones Unidas para el Desarrollo, 2010).

Sin embargo, no hay estudios donde se indique cuánto realmente afecta esta distribución laboral a la brecha salarial en Chile. Este sería el primer acercamiento a esta incógnita. Este resultado es mucho mayor al encontrado en Portugal, donde la distribución de mujeres en el mercado laboral explica el $15-20 \%$ de la brecha.

\section{Regulación}

Al realizar la regresión de la ecuación (7), se estima el coeficiente de interés que indica el efecto de la Ley 20.348 en las mujeres trabajadoras después de julio del año 2009, es decir, el efecto del tratamiento en el grupo tratado.

El modelo entrega un coeficiente igual a $0,00647^{14}$, lo que concuerda con la literatura que ha estudiado el efecto de esta ley. Como indica Henríquez y Riquelme (2011) esta ley ha tenido bajo conocimiento entre los empleadores y trabajadores. Además la ley no involucra a los sindicatos, que podrían ser fundamentales para que la regulación funcione, dado que en la práctica muchas mujeres no van a reclamar ya que pueden quedar como conflictivas, lo que pone en riesgo sus trabajos.

Este resultado se suma a lo concluido en el infor-

\footnotetext{
${ }^{14}$ Por limitaciones computacionales no se pudo sacar la significancia del estimador.
}

me realizado por el Comité de Evaluación de la Ley en el año 2013, donde se concluye que la Ley 20.348 ha sido ineficiente en disminuir la brecha salarial de género (Figura 1) debido a su desconocimiento $\mathrm{y}$ falta de incentivos.

\section{Limitaciones}

Los efectos fijos firma (premio salarial) que se utilizaron en los resultados ob-tenidos en el Cuadro 7 están limpiados de cualquier diferencia permanente de los trabajadores de ambos géneros (efecto fijo persona).

Por otra parte, todas las firmas usadas en el análisis que contratan hombres y mujeres están conectadas con otras firmas que contratan hombres y mujeres a través de la movilidad del trabajo, por lo que se utiliza una descomposición con soporte común. Sin embargo, hay dos limitaciones que mencionar.

La primera limitación es que las descomposiciones se basan en el supuesto que el premio salarial (efecto empresa) es igual a cero para las empresas que se encuentran en el $5 \%$ inferior del indice de calidad para ambos géneros. En la medida que los trabajadores hombres de estas empresas reciban un premio salarial mayor al de las mujeres, los resultados del Cuadro 7 son estimaciones del límite inferior del impacto del menor poder de negociación de las mujeres; es decir, el poder de negociación podría tener un mayor efecto en la brecha salarial de género. 
Cuadro 5: Resumen de las estimaciones del modelo de dos efectos fijos para trabajadores masculinos y femeninos.

\begin{tabular}{|c|c|c|c|c|}
\hline & \multicolumn{2}{|c|}{ Muestra con datos de educación } & \multicolumn{2}{|c|}{ Muestra sin datos de educación } \\
\hline & Hombres & Mujeres & Hombres & Mujeres \\
\hline Desviación estandar de log salario & 0,826 & 0,829 & 0,847 & 0,861 \\
\hline Número de observaciones & 5.877 .508 & 3.045 .183 & 7.266 .268 & 4.323 .800 \\
\hline \multicolumn{5}{|l|}{ Resumen de parámetros estimados: } \\
\hline Número efecto persona & 111.140 & 63.714 & 157.118 & 112.956 \\
\hline Número efecto firma & 47.422 & 41.315 & 50.699 & 47.421 \\
\hline Efecto persona & 0,442 & 0,490 & 0,507 & 0,560 \\
\hline Efecto firma & 0,376 & 0,356 & 0,371 & 0,347 \\
\hline$X_{i t}^{\prime} \beta^{g}$ & 0,213 & 0,197 & 0,194 & 0,183 \\
\hline Correlación efecto persona/firma & 0,117 & 0,052 & 0,168 & 0,144 \\
\hline RMSE de modelo AKM & 0,468 & 0,472 & 0,450 & 0,452 \\
\hline R-cuadrado ajustado de modelo AKM & 0,669 & 0,665 & 0,708 & 0,712 \\
\hline \multicolumn{5}{|c|}{ Descomposición de la varianza de log salario: } \\
\hline Efecto persona & 28,6 & 34,9 & 35,8 & 42,3 \\
\hline Efecto firma & 20,8 & 18,5 & 19,2 & 16,2 \\
\hline Covarianza de efecto firma y persona & 2,8 & 1,3 & 4,4 & 3,8 \\
\hline$X_{i t}^{\prime} \beta^{g}$ y covarianzas asociadas & 15,6 & 12,9 & 12,3 & 10,1 \\
\hline Residuos & 32,2 & 32,4 & 28,3 & 27,6 \\
\hline Total & 100 & 100 & 100 & 100 \\
\hline
\end{tabular}

Nota: (1) Regresión de la muestra con educación se hizo mediante el comando a2reg (Ouazad, 2008) donde se incluyo dummies de años que interactúan con dummies de educación y edad interactuando con educación lo cual hizo un total de 54 parámetros. (2) Regresión de la muestra sin educación tiene 12 dummies de años y 3 parámetros de educación. (3) AKM: Abowd, Creecy y Kramarz (2002).

Cuadro 6: Descomposición de la brecha salarial de género.

\begin{tabular}{lccc}
\hline & Mujeres & Hombres & Brecha salarial de género \\
\hline \hline Datos & 7,803 & 8,077 & $-0,274$ \\
\hline 1. Promedio de Log salarial & & & \\
Contrafactuales & 7.876 & 8,077 & $-0,201$ \\
$\begin{array}{l}\text { 2. Asumiendo Efecto Firma masculino en el salario Femenino } \\
\quad \text { porcentaje explicado de la brecha salarial) }\end{array}$ & & $(26,6)$ \\
3. Asumiendo Efecto Firma femenino en el salario de Masculino & 7,803 & 8,000 & $-0,197$ \\
$\quad$ (porcentaje explicado de la brecha salarial) & & & $(28,1)$ \\
4. Asumiendo Distribución masculino, a través de las firmas & 8,015 & 8,077 & $-0,062$ \\
$\quad$ (porcentaje explicado de la brecha salarial) & & & $(77,4)$ \\
5. Asumiendo Distribución femenino, a través de las firmas & 7,803 & 7,960 & $-0,157$ \\
$\quad$ (porcentaje explicado de la brecha salarial) & & & $(42,7)$ \\
\hline \hline
\end{tabular}

El segundo punto a tener en cuenta es sobre las limitaciones que tiene la muestra utilizada, dado que tuvo que ser recortada una serie de veces por distintos motivos.

Como se mencionó anteriormente, no toda la muestra tenía información sobre educación, solo el $76,4 \%$. Luego, el análisis de movilidad se limitó a individuos que hubieran estado al menos dos años en la firma de origen y dos años en la empresa de destino. Además, solo se tomó empresas que contrataran hombres y mujeres excluyendo a las firmas que solo emplean trabajadores de un solo sexo. El $23,5 \%$ de las observaciones pertenecen a empresas que solo tienen empleados hombres o mujeres. Esto se debe a que la muestra es aleatorizada por individuos y no por empresas, lo que hace que un grupo de firmas tengan datos de 1 o 2 empleados. Como se señaló anteriormente, no se tiene información del tamaño de las empresas y este es estimado por el número de observaciones firma-trabajador que haya por empresa. Estas limitaciones podrían ser resueltas teniendo mayor información como, por ejemplo, el tamaño de las empresas y el número de contratos.

\section{Conclusiones}

Parte de la nueva literatura ha sugerido que la brecha salarial de género puede ser explicada en parte por diferencias en habilidades y voluntades de las mujeres en la negociación con sus empleadores sobre el salario (Marianne, 2011).

Este trabajo, utilizando la metodología desarrollada por Card, Cardoso y Kline (2013a) y usando una extensa base de datos donde se observa a trabajadores en distintas firmas en el tiempo, logra medir el efecto del poder de negociación sobre la brecha salarial de género.

Una de las claves del modelo presentado en este trabajo es el reconocimiento de que existe un componente en cada empresa que impulsa a la negociación sobre salarios individuales a hombres y mujeres. 


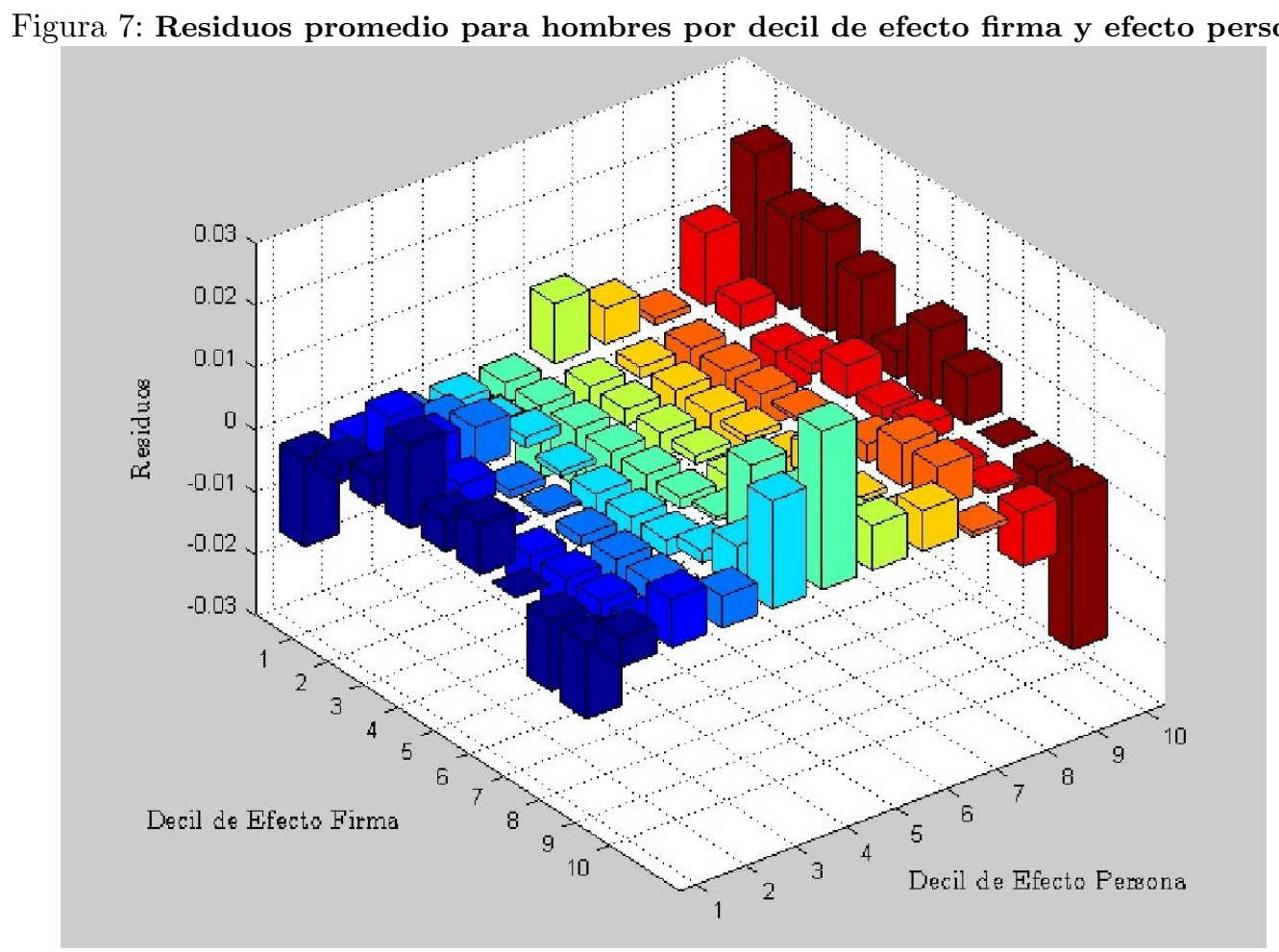

Fuente: Elaboración propia.

En Chile, la diferencia salarial de género es del $27,4 \%$ y esta hipótesis explica entre el $27 \%$ y el $28 \%$ de la brecha, superando el resultado encontrado en Portugal (Card et al., 2013a). Además, se encuentra que las mujeres aumentan su salario aproximadamente un $15 \%$ menos, en promedio, que los hombres al cambiarse de firma.

Gracias a distintas investigaciones es posible entender de mejor manera por qué el poder de negociación puede afectar la brecha salarial de género.

Por ejemplo, Gilbreath y Powers (2006) señalan que el $63 \%$ de los hombres tienen un salario inicial más alto que sus compañeras mujeres. Tales diferencias iniciales de salario tienen implicancias significativas en la brecha salarial en el tiempo (Babcock y Laschever, 2009). Estas diferencias en las negociaciones en el salario inicial de hombres y mujeres pueden explicar una parte de la brecha salarial de género.

Bowles, et al. (2005) en su estudio señalan que el $57 \%$ de los hombres recién graduados de un master de la Universad Carnegie Mellon intentan negociar un salario más alto con el empleador; en cambio, sólo el $7 \%$ de las mujeres lo hace.

En este mismo sentido, Babcock et al. (2006) llegan a la conclusión de que los hombres inician una negociación 2 a 3 veces más que las mujeres, lo que sugiere que los hombres son más propensos a ini- ciar una negociación. Sin embargo, hay muy poca evidencia empírica sobre cuánto afecta el poder de negociación a la brecha salarial (Kray y Thompson, 2004).

Rigdon (2012) propone dos razones para el menor poder de negociación de las mujeres: las mujeres piden menos salario y ganan menos que sus homólogos masculinos. Además, las mujeres tienen menos probabilidad de iniciar una negociación y son menos efectivas al negociar que los hombres. La literatura sugiere que esto puede ocurrir dado que las mujeres pueden sentirse menos merecedoras de un premio monetario o porque esperan una reacción violenta si negocian por un derecho que les pertenece (Rudman y Glick, 1999).

Algo que puede ayudar a disminuir la diferencia en el poder de negociación es entregar información de las demandas sociales hechas por otros en situaciones similares, lo que influye directamente en las creencias de las mujeres sobre las normas de negociación que tienen. Esto haría que pidan más salario, eliminando la brecha de negociación (Rigdon, 2012).

En Chile existe una brecha salarial de $27,4 \%$, en cambio; en Portugal es de $23,4 \%$. Esto indica que en Chile las mujeres ganan menos que los hombres, lo que podría explicar el menor poder de negociación femenino y su mayor impacto en la brecha salarial. 
Figura 8: Residuos promedio para mujeres por decil de efecto firma y efecto persona

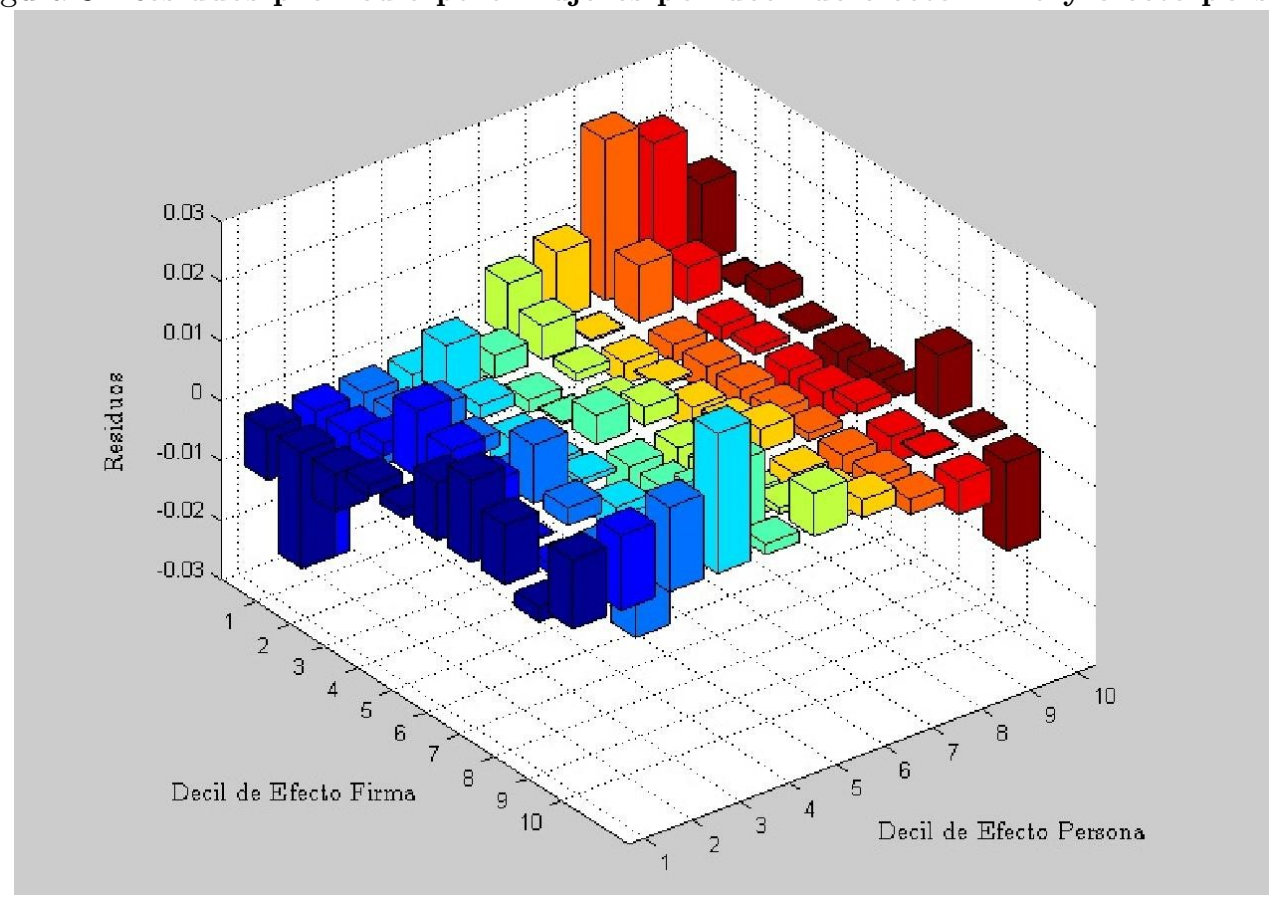

Fuente: Elaboración propia.

Algunos datos permiten entender las razones de la diferencia entre los resultados de Portugal y Chile. Cardoso, Guimaraes y Portugal (2012) señalan que el patrón de la tasa de actividad femenina en Portugal es muy similar al de los hombres, a diferencia de lo que ocurre en varios otros países europeos, especialmente del sudeste (península de los Balcanes).

En particular alrededor del parto y durante la crianza de los hijos, las mujeres en Portugal no muestran una disminución de su participación en la fuerza laboral. Además, las horas trabajadas de hombres y mujeres son muy similares.

Asimismo en Portugal, al igual que en otros países europeos, todos los años se definen pisos salariales para 300 diferentes categorías profesionales a través de ne-gociaciones colectivas. Estos acuerdos de salarios no pueden ser inferiores al salario mínimo de Portugal.

Por otro lado, en Chile durante los últimos veinte años la mujer ha tenido una alta incorporación a la fuerza laboral, pero existen algunas consideraciones que hay que tener en cuenta. Por ejemplo, la incorporación de la mujer no ha sido homogénea, existe segregación de género en las industrias (Henriquez y Riquelme, 2011). Muchas veces esto ha hecho que las mujeres estén en trabajos de menor calidad que los hombres. La Encuesta Suplementaria de Ingresos del año 2011 indica que en los sectores con alta concentración femenina es amplia la franja de tra- bajo precario e informal, con baja productividad y mal pagado.

Las diferencias que existen en el mercado laboral de Portugal y Chile pueden explicar en cierta parte la gran diferencia que existe en los resultados encontrados en Chile en comparación con los de Card, Cardoso y Kline (2013a).

Este trabajo aporta a la literatura que señala que la empresa es fundamental en el proceso de determinación del salario (Lentz y Mortensen, 2010). Los resultados encontrados son evidencia sobre la importancia de las políticas salariales específicas de las empresas y muestran que una parte significativa de la brecha salarial de género surge directamente a través de componentes de las firmas.

Como se señala en European Union (2014), la eliminación de la brecha salarial entre hombres y mujeres contribuiría a reducir los niveles de pobreza y a aumentar los ingresos que reciben las mujeres a lo largo de su vida laboral, sino que también se reduciría el riesgo de pobreza tras la jubilación. Como se indica en Henríquez y Riquelme (2011) la participación laboral femenina en Chile ha aumentado considerablemente durante las últimas dos décadas. Además, la mujer ha pasado a aportar un mayor porcentaje del ingreso del hogar, especialmente, en las familias más pobres. Sin embargo, la mujer recibe menor ingreso que los hombres por un mismo trabajo y como se indica en este estudio, el poder de negociación explica un cuarto de esta brecha, por 
Figura 9: Relación entre efecto fijo promedio de hombres y mujeres para cada grupo de firmas según su calidad

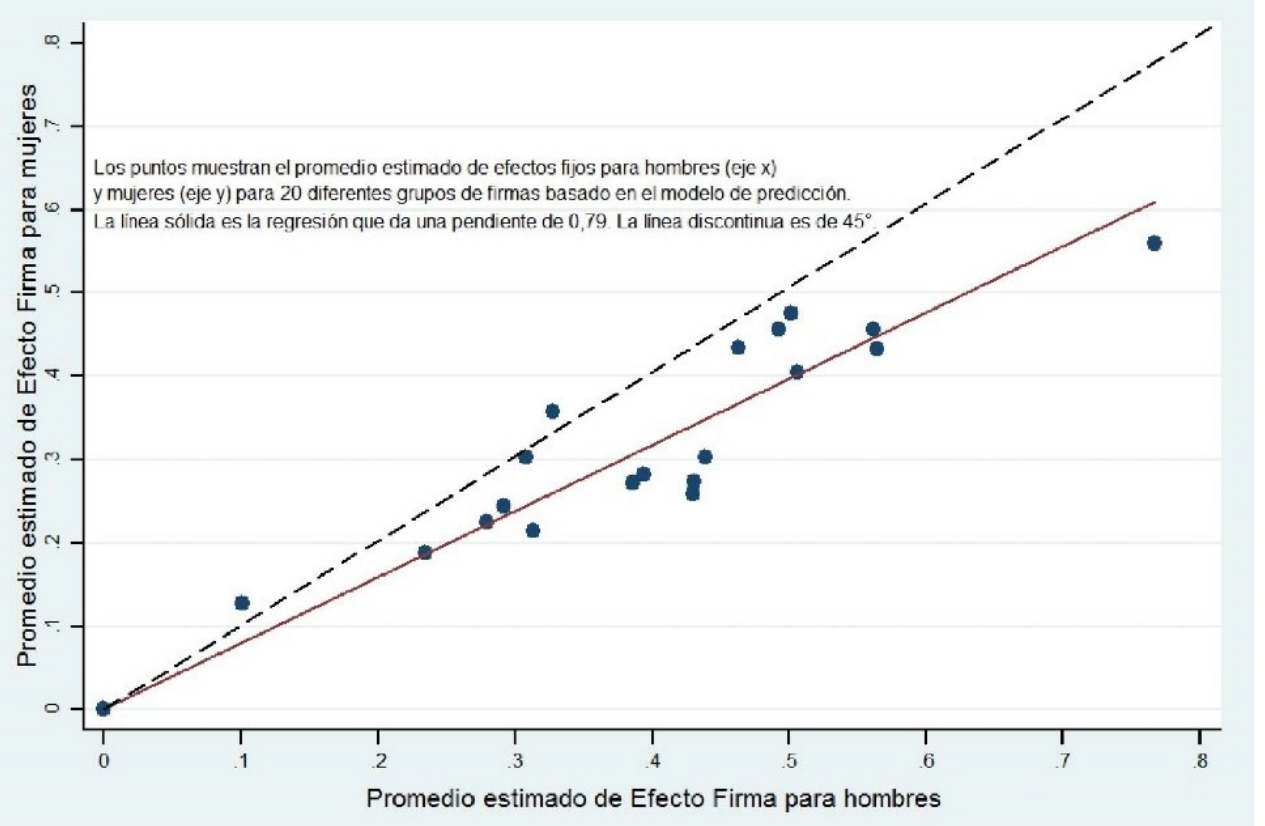

Fuente: Elaboración propia.

lo que empoderar a la mujer en su trabajo ayudaría a disminuir esta diferencia salarial.

Por último, sería interesante tener una base de datos con mayor información del empleador, lo que permitiría observar qué pasa con el poder de negociación cuando la empresa aumenta o disminuye sus utilidades. Ello también permitiría realizar un mejor modelo de predicción, obteniendo un índice de calidad más certero.

Un gran aporte sería realizar este tipo de investigación en otros países latinoamericanos para poder comparar resultados con otros países parecidos a Chile. También se podría realizar el estudio en países como Francia, Dinamarca, Noruega, Italia y Brasil, donde existen bases de datos que permiten estudiar el efecto del poder de negociación sobre la brecha salarial de género.

\section{Referencias}

Abowd, J., Creecy, R., y Kramarz, F. (2002). Computing Person and Firm Effects Using Linked Longitudinal Employer-Employee Data. IDEAS Working Paper Series from RePEc.

Abramo, L. W. y Todaro, R. (2002). Cuestionando un mito: costos laborales de hombres y mujeres en América Latina. Oficina Internacional del Trabajo, Oficina Regional para América Latina y el Caribe.
Altonji, J. G. y Blank, R. M. (1999). Race and gender in the labor market. Handbook of labor economics, 3:3143-3259.

Babcock, L., Gelfand, M. J., Small, D., y Stayn, H. (2006). Propensity to initiate negotiations: A new look at gender variation in negotiation behavior. En De Cremer, D., Zeelenberg, M., y Murnighan, J. K., editores, Social Psychology Economics, pp. 239 - 262. Lawrence Erlbaum Associates, Mahwah, New Jersey.

Babcock, L. y Laschever, S. (2009). Women don't ask: Negotiation and the gender divide. Princeton University Press.

Bowles, H. R., Babcock, L., y McGinn, K. L. (2005). Constraints and triggers: situational mechanics of gender in negotiation. Journal of personality and social psychology, 89(6):951.

Burdett, K. y Mortensen, D. T. (1998). Wage differentials, employer size, and unemployment. International Economic Review, pp. 257-273.

Card, D., Cardoso, A., y Kline, P. (2013a). Bargaining and the Gender Wage Gap: A Direct Assessment. IDEAS Working Paper Series from RePEc.

Card, D., Heining, J., y Kline, P. (2013b). Workplace Heterogeneity and the Rise of West German Wage Inequality. The Quarterly Journal of Economics, 128(3):967. 
Cardoso, A., Guimaraes, P., y Portugal, P. (2012). Everything You Always Wanted to Know about Sex Discrimination. IDEAS Working Paper Series from RePEc.

de las Naciones Unidas para el Desarrollo, P. (2010). Desarrollo humano en Chile 2010: los desafíos de la igualdad. Santiago.

Dinardo, J., Fortin, N. M., y Lemieux, T. (1996). Labor Market Institutions and the Distribution of Wages, 1973-1992: A Semiparametric Approach. Econometrica, 64(5):1001-1044.

Gilbreath, K. y Powers, S. (2006). Starting Salaries of College Graduates. Journal of Legal Economics, 13(2):79-95.

Gruetter, M. y Lalive, R. (2009). The importance of firms in wage determination. Labour Economics, 16(2):149-160.

Henriquez, H. y Riquelme, V. (2011). El derecho a ganar lo mismo ley 20.348: Igualdad de remuneraciones entre hombres y mujeres. Temas Laborales, 27.

Jarrell, S. B. y Stanley, T. D. (2004). Declining Bias and Gender Wage Discrimination? A MetaRegression Analysis. The Journal of Human Resources, 39(3):828-838.

Katz, L. F. (1999). Changes in the wage structure and earnings inequality. Handbook of labor economics, 3:1463-1555.
Kray, L. J. y Thompson, L. (2004). Gender stereotypes and negotiation performance: an examination of theory and research. Research in Organizational Behavior, 26:103-182.

Lentz, R. y Mortensen, D. T. (2010). Labor market models of worker and firm heterogeneity. Annu. Rev. Econ., 2(1):577-602.

Marianne, B. (2011). New perspectives on gender. Handbook of labor economics, 4:1543-1590.

Oaxaca, R. (1973). Male-Female Wage Differentials in Urban Labor Markets. International Economic Review, 14:693.

Ouazad, A. (2008). A2REG: Stata module to estimate models with two fixed effects.

Rau, T. (2010). El trabajo a tiempo parcial en Chile. Economía chilena, 13(1):38-59.

Rigdon, M. L. (2012). An Experimental Investigation of Gender Differences in Wage Negotiations. Available at SSRN 2165253.

Rudman, L. A. y Glick, P. (1999). Feminized management and backlash toward agentic women: the hidden costs to women of a kinder, gentler image of middle managers. Journal of personality and social psychology, 77(5):1004. 